

\title{
Preferential Activation of CO near Hydrocarbon Chains during Fischer-Tropsch Synthesis on Ru
}

\author{
David Hibbitts ${ }^{\mathrm{a}, \mathrm{b}}$, Eric Dybeck ${ }^{\mathrm{c}}$, Thomas Lawlor ${ }^{\mathrm{c}}$, Matthew Neurock ${ }^{\mathrm{c}, \mathrm{d}^{*}}$, and Enrique Iglesia ${ }^{\mathrm{a} *}$ \\ ${ }^{a}$ Department of Chemical and Biomolecular Engineering, University of California, Berkeley, CA, 94720, United States \\ ${ }^{\mathrm{b}}$ Present Address: Department of Chemical Engineering, University of Florida, Gainesville, FL, 32611, United States \\ ${ }^{\mathrm{c}}$ Department of Chemical Engineering, University of Virginia, Charlottesville, VA, 22904, United States \\ ${ }^{\mathrm{d}}$ Department of Chemical Engineering and Materials Science, University of Minnesota, Minneapolis, MN, 55455, United States \\ * Corresponding authors. mneurock@umn.edu (M. Neurock) and iglesia@berkeley.edu (E. Iglesia).
}

\begin{abstract}
We report here theoretical evidence for an enhancement in $\mathrm{CO}$ activation to form $\mathrm{C}_{1}$ monomers at locations near growing hydrocarbon chains as a result of their ability to disrupt the dense monolayers of chemisorbed CO* present during Fischer-Tropsch synthesis (FTS). These previously unrecognized routes become favored at the high $\mathrm{CO}^{*}$ coverages that prevail on curved cluster surfaces at conditions of FTS practice and account for the rapid growth of chains, which requires a source of vicinal monomers. $\mathrm{CO}$ activation initially requires a vacant site (and consequently $\mathrm{CO}^{*}$ desorption) and proceeds via $\mathrm{CO}^{*}$ reactions with $\mathrm{H}^{*}$ to form hydroxymethylene $\left(\mathrm{CH}^{*} \mathrm{OH}^{*}\right)$, which and then dissociates to form $\mathrm{OH}^{*}$ and $\mathrm{CH}^{*} ; \mathrm{CH}_{\mathrm{x}}{ }^{*}$ species can subsequently act as monomers and insert into chains, a process denoted as the 'carbene' mechanism. These $\mathrm{CH}^{*}$, and their larger alkylidyne $\left(\mathrm{C}_{n} \mathrm{H}_{2 n-1}{ }^{*}\right)$ homologs, disrupt the dense $\mathrm{CO}^{*}$ adlayers and in doing so allow the vicinal facile formation of the $\mathrm{CH}^{*} \mathrm{OH}^{*}$ intermediates that mediate $\mathrm{CO}$ activation, without requiring, in this case, $\mathrm{CO}^{*}$ desorption. This causes $\mathrm{CO}^{*}$ activation effective enthalpy and free energy barriers to be $\sim 100$ and $\sim 15 \mathrm{~kJ} \mathrm{~mol}^{-1}$ lower, respectively, near growing chains than within unperturbed monolayers. These effects are observed near alkylidyne $\left(\mathrm{C}_{n} \mathrm{H}_{2 n-1}{ }^{*}\right)$ but not alkylidene $\left(\mathrm{C}_{n} \mathrm{H}_{2 n}{ }^{*}\right)$ or alkyl $\left(\mathrm{C}_{n} \mathrm{H}_{2 n+1}{ }^{*}\right)$ chains. These phenomena cause monomers to form preferentially near growing alkylidyne chains, instead of at undisrupted regions of $\mathrm{CO}^{*}$ monolayers, causing chain growth (via $\mathrm{CH}_{x}{ }^{*}$-insertion) to occur much more rapidly than chain initiation, a requirement to form long chains. Such routes resolve the seemingly contradictory proposals that $\mathrm{CH}_{\mathrm{x}}{ }^{*}$ species act as monomers (instead of $\mathrm{CO}^{*}$ ) and chain initiators, but their formation and diffusion on dense $\mathrm{CO}^{*}$ adlayers must occur much faster than chain initiation for such chains to grow fast and reach large average lengths. Chains disrupt surrounding molecules in the adlayer, causing faster monomer formation precisely at locations where they can readily react with growing chains. This work illustrates how interactions between transition states and co-adsorbates can dramatically affect predicted rates and selectivities at the high coverages relevant to practical catalysis.
\end{abstract}

\section{Introduction}

Fischer-Tropsch synthesis (FTS) converts synthesis gas mixtures ( $\mathrm{CO}$ and $\left.\mathrm{H}_{2}\right)$ to hydrocarbons on $\mathrm{Fe}, \mathrm{Co}$, and Ru catalysts [1-3]; it is a process critical to the success of many strategies for the conversion of natural gas, biomass, and $\mathrm{CO}_{2}$ to fuels, energy carriers, and chemicals. Hydrocarbon chains are initiated by $\mathrm{CO}$ activation on metal surfaces; these chains propagate by adding $\mathrm{CO}$-derived monomers 
and terminate via desorption as alkenes, alkanes, and mixtures of oxygenates [2-4]. Kinetic [5-7], infrared [8,9], isotopic switch [4], and theoretical studies [8] indicate that these reactions occur on surfaces nearly saturated with chemisorbed $\mathrm{CO}(\mathrm{CO} *)$.

Recent studies have confirmed that $\mathrm{CO}$ activation occurs via $\mathrm{H}$-assisted routes that form hydroxymethylene $\left(\mathrm{CH}^{*} \mathrm{OH}^{*}\right)$ species before the cleavage of the $\mathrm{C}-\mathrm{O}$ bond on $\mathrm{Co}$ and $\mathrm{Ru}[6,8,10,11]$. $\mathrm{CH}^{*} \mathrm{OH}^{*}$ dissociates to form $\mathrm{CH}^{*}$ species that hydrogenate to form $\mathrm{CH}_{\mathrm{x}} *$ (and ultimately $\mathrm{CH}_{4}$ ) or react with a $\mathrm{CO}^{*}$-derived monomer $\left(\mathrm{C}_{1} *, \mathrm{CO}^{*}\right.$ or $\left.\mathrm{CH}_{\mathrm{x}} *\right)$ to form $\mathrm{C}-\mathrm{C}$ bonds; the $\mathrm{OH}^{*}$ formed via $\mathrm{CH}^{*} \mathrm{OH}^{*}$ dissociation results in $\mathrm{H}_{2} \mathrm{O}$ co-products [6,8,10-12]. Such mechanistic consensus is not apparent for $\mathrm{C}-$ $\mathrm{C}$ bond formation routes. ${ }^{12} \mathrm{CO} /{ }^{13} \mathrm{CO}$ isotopic switch data have shown that alkenes form with similar isotopic content at each location along the backbone, indicating that all of its $\mathrm{C}$-atoms were added within a period of time much shorter than the time required to replace $\mathrm{CO}^{*}$ reactant with a given carbon isotope [4]. These data indicate that a small number of chains grow rapidly on surfaces during FTS, via a process that appears to require the rapid formation of monomers within diffusion distances from growing chains.

Hydrocarbon chains can react with vicinal $\mathrm{CO}^{*}$ in $\mathrm{CO}$-insertion routes that form $\mathrm{C}-\mathrm{C}$ bonds and $\mathrm{CH}_{\mathrm{x}} \mathrm{CO} *$ species; the latter may desorb after $\mathrm{H}$-addition to form alkanals and alkanols or cleave its $\mathrm{C}-\mathrm{O}$ bond to form precursors to alkenes and alkanes [13-18]. The rapid chain growth processes discussed above could plausibly occur via $\mathrm{CO}^{*}$-insertion because of readily available vicinal $\mathrm{CO}^{*}$ when chains grow on $\mathrm{CO}^{*}$-saturated surfaces; theoretical treatments of such routes will be reported in a separate manuscript at a later time.

$\mathrm{CH}_{\mathrm{x}} *$ addition to growing chains can also form $\mathrm{C}-\mathrm{C}$ bonds, as inferred from the incorporation of $\mathrm{CH}_{2}{ }^{*}$ species derived from $\mathrm{CH}_{2} \mathrm{~N}_{2}$ into the hydrocarbons formed from $\mathrm{H}_{2}-\mathrm{CO}$ reactants [19,20], via a process that has been denoted as the carbene route [21-26]. These $\mathrm{CH}_{\mathrm{x}} *$ species form from $\mathrm{CO} *$ via the same $\mathrm{H}^{*}$-assisted $\mathrm{CO}$ cleavage that initiates chains. For fast chain growth [4], such $\mathrm{CH}_{\mathrm{x}}$-insertion propagation routes would require that $\mathrm{CO}$ activation steps be much faster than the corresponding steps that initiate chains and that $\mathrm{CH}_{\mathrm{x}}{ }^{*}$ species, some with multiple covalent surface attachments, diffuse very rapidly on $\mathrm{CO}^{*}$-saturated surfaces.

Here, we provide theoretical evidence for an alternate route that involves the preferential $\mathrm{H}$-assisted activation of $\mathrm{CO}^{*}$ molecules that reside next to a growing chain. Such processes are made possible through a disruption of dense $\mathrm{CO}^{*}$ monolayers by such growing chains, which lead to an "activation 
space"; this space avoids the need to desorb an additional $\mathrm{CO}^{*}$, which carries a significant enthalpic penalty, to ameliorate the repulsive forces that destabilize transition states at high $\mathrm{CO}^{*}$ coverages. These first-principles density functional theory (DFT) calculations show that enthalpy and free energy barriers for $\mathrm{H}^{*}$-assisted $\mathrm{CO}^{*}$ activation on $\mathrm{Ru}$ surfaces are lower for activating $\mathrm{CO}^{*}$ vicinal to hydrocarbon chains, via monolayer disruption phenomena that are likely to prevail at the $\mathrm{CO}^{*}$ coverages required for significant chain growth from $\mathrm{H}_{2}-\mathrm{CO}$ reactants on other FTS catalysts. These seemingly unrecognized processes allow fast $\mathrm{CH}_{\mathrm{x}}{ }^{*}$ mediated chain propagation to readily occur via preferential monomer formation near growing chains and thus account for the rapid chain growth observed experimentally but inconsistent with the carbene route. More generally, the results presented herein indicate that dense adlayers, ubiquitous in the practice of catalysis, significantly influence the steric and electronic properties of sites and intermediates and thus the reactivity of adsorbates, an essential feature often ignored in fundamental studies carried out on model surfaces at low surface coverages.

\section{Methods}

Periodic plane-wave DFT methods implemented in the Vienna ab initio simulation package (VASP) [27-30] were used to calculate adsorption and reaction energies and activation barriers for elementary steps involved in $\mathrm{CO}^{*}$ activation and $\mathrm{CH}_{\mathrm{x}} *$ formation. Plane-waves were constructed using projector augmented-wave (PAW) potentials with an energy cutoff of $400 \mathrm{eV}[31,32]$. The revised Perdew-BurkeErnzerhof (RPBE) form of the generalized gradient approximation (GGA) was used to determine exchange and correlation energies [33-35]. Furthermore, calculations were carried out using optB86bvdW[36] and vdw-DF2[37] GGA functionals to describe dispersion forces among atoms. Similar dispersive interactions were incorporated into RPBE calculations using DFT-D3 with Becke and Johnson (BJ) damping [38,39]. DFT-D3 was also used to determine interactions among non-metal atoms $(\mathrm{C}, \mathrm{O}$, and $\mathrm{H})$ to correct for dispersive interactions only between co-adsorbates, as the parameters for the DFT-D3 method were primarily based on interactions of gas-phase species [38,39]. Wavefunctions were converged to within $10^{-6} \mathrm{eV}$ and forces were computed using a fast Fourier transform (FFT) grid with a cutoff of twice the planewave cutoff. A 1 × 1 x 1 Monkhorst-pack sampling of the first Brillouin zone (k-point mesh) was used [40] and structures were relaxed until forces on unconstrained atoms were < $0.05 \mathrm{eV} / \AA$.

A 586-atom $\mathrm{Ru}$ cubo-octahedral particle $(\sim 2.5 \mathrm{~nm}$ in diameter) was used in the calculations at 1.04 $\mathrm{CO} * / \mathrm{Ru}$ coverages ( $284 \mathrm{CO}^{*}$ on 272 surface $\mathrm{Ru}$ atoms) to account for sites with different coordination 
and relevant $\mathrm{CO}^{*}$ coverages. Edge and corner atoms of low coordination (96 atoms) on $\mathrm{Ru}_{586}$ stabilized bridge-bound $\mathrm{CO}^{*}$ species (108 $\mathrm{CO}^{*}$ species) that lead to supramonolayer coverages (Fig. 1) through the formation of gem-dicarbonyl species as observed with infrared experiments [8]. The high saturation coverages found here are fully consistent with in-situ infrared studies [8,9,41], isotopic switch experiments [4], transient kinetic studies [6] and previous FTS kinetic studies [5-7] that all indicate that the $\mathrm{Co}$ and $\mathrm{Ru}$ surfaces are fully covered in CO at FTS conditions. CO peak intensities measured on Ru with in situ infrared spectroscopy no longer increase with increasing $\mathrm{CO}$ pressures above $\sim 0.5 \mathrm{kPa} \mathrm{CO}$ even at higher temperatures $(548-598 \mathrm{~K})$ than those associated with FTS $(\sim 500 \mathrm{~K})$, indicating that surfaces are saturated at such pressures [41] Furthermore $\mathrm{CO}$ hydrogenation rates on $\mathrm{Ru}$ obtained at near-methanation conditions $(548-598 \mathrm{~K}$ and $0.01-10 \mathrm{kPa} \mathrm{CO})$ show that hydrogenation becomes inhibited by $\mathrm{CO}$ (indicating $\mathrm{CO}^{*}$ coverages exceed $0.5 \mathrm{ML}$ ) at less than $0.1 \mathrm{kPa} \mathrm{CO}$ [41]. This is consistent with UHV studies that indicate saturation coverages of $\sim 0.9 \mathrm{ML} \mathrm{CO}^{*}$ are reached at $10^{-2}$ Torr [42]. Rigorous FTS kinetic studies on Ru [8] and Co [6] also show that the rates of FTS are inhibited by increasing $\mathrm{CO}$ pressure which is a direct result of the dominance of the $\mathrm{K}_{\mathrm{CO}}(\mathrm{CO})$ term in the denominator of the rate equation:

$$
r=\frac{\alpha\left(\mathrm{H}_{2}\right)(\mathrm{CO})}{\left[1+\mathrm{K}_{\mathrm{CO}}(\mathrm{CO})\right]^{2}}
$$

At conditions typical of FTS, the surface is fully covered in $\mathrm{CO}$ and thus $\mathrm{K}_{\mathrm{CO}}(\mathrm{CO})$ is $\gg 1$, leading to rates inversely proportional to $\mathrm{CO}$ pressure:

$$
r=\frac{\alpha\left(\mathrm{H}_{2}\right)}{\mathrm{K}_{\mathrm{CO}}(\mathrm{CO})}
$$

The bottom six layers of the $\mathrm{Ru}_{586}$ cluster were removed along the (111) surface and the bottom two layers of this structure and their $\mathrm{CO}^{*}$ species were not allowed to relax during the calculations in order to decrease the computational demands and thus be able to explore a wider range of plausible intermediates and routes (Fig. 1). This $\mathrm{Ru}_{218}$ polycrystalline model was used for all calculations reported.

Figure 1. $\mathrm{Ru}_{586}$ nanoparticle at $1.04 \mathrm{ML} \mathrm{CO} *$ along with the (111) plane used to cleave the catalyst model into a more computationally-feasible $\mathrm{Ru}_{218}$ structure with four metal layers orthogonal to the closed-packed terrace. 
Transition state structures obtained for elementary steps were explored using nudged elastic band (NEB) methods [43,44] and then refined using dimer methods [45]. NEB methods used 16 images and wavefunctions converged to $10^{-4} \mathrm{eV}$ with a FFT grid 1.5 times the size of the plane-wave cutoff. Maximum forces on each atom were converged to $<0.3 \mathrm{eV} / \AA$. The dimer algorithm was then used with wavefunctions converged to $<10^{-6} \mathrm{eV}$ and a FFT grid size twice the planewave cutoff and converged to a maximum force of $<0.05 \mathrm{eV} / \AA ̊ \AA$ on each atom.

Frequency calculations were carried out on all optimized states to determine zero-point vibrational energies $(Z P V E)$, vibrational enthalpies $\left(H_{v i b}\right)$, and free energies $\left(G_{v i b}\right)$. Their values were used, together with VASP-derived electronic energies $\left(E_{0}\right)$, to obtain enthalpies:

$$
H=E_{0}+Z P V E+H_{\text {vib }}+H_{\text {trans }}+H_{\text {rot }}
$$

and free energies:

$$
G=E_{0}+Z P V E+G_{v i b}+G_{t r a n s}+G_{r o t}
$$

for all reactant, product, and transition state structures. For RPBE GGA, the dispersion-corrected enthalpies:

$$
H=E_{0}+E_{d}+Z P V E+H_{\text {vib }}+H_{\text {trans }}+H_{\text {rot }}
$$

and free energies:

$$
G=E_{0}+E_{d}+Z P V E+G_{v i b}+G_{\text {trans }}+G_{\text {rot }}
$$

were also calculated, where $E_{d}$ is the dispersive energy between all $\mathrm{C}, \mathrm{O}$, and $\mathrm{H}$ atoms estimated by DFT-D3(BJ) methods [38,39]. For gaseous molecules, translational and rotational enthalpies and free energies were computed from statistical mechanics. The equations used to determine ZPVE, $H_{v i b}$, and $G_{v i b}$ from vibrational frequencies for all species and $H_{\text {trans }}, H_{r o t}, G_{\text {trans }}$, and $G_{r o t}$ from statistical mechanics formalisms for gas-phase molecules are reported in the Supporting Information (SI; Equations S1-S13).

\section{Results and Discussion}

\subsection{Theoretical Treatments of Dense Monolayers of Chemisorbed CO on Ru Particles}

The construction and analysis of relevant surfaces and of the elementary steps that they mediate require that we consider the number, configurations and binding energies of the $\mathrm{CO}^{*}$ species that form the monomers involved in chain growth and that we do so on surfaces with $\mathrm{CO} *$ coverages of practical 
interest. Particle models allow for a more rigorous examination of the effects of surface atom coordination and of surface and adsorbate relaxations without the unphysical lateral rigidity imposed by flat extended models [8,10]. FTS turnover rates on $\mathrm{Co}[2,46]$ and $\mathrm{Ru}$ [47] catalyst increase with increasing particle size and then reach constant values for particles larger than $10 \mathrm{~nm}$, indicating that turnovers occur predominantly on low-index planes that prevail on larger particles. Smaller particles contain significant fractions of defect sites that can activate $\mathrm{CO}^{*}$ to form strongly-bound $\mathrm{C}^{*}$ and $\mathrm{O}^{*}$ species which ultimately deactivate such particles and may lead to bulk oxidation.[2] DFT-calculated differential $\mathrm{CO}$ adsorption enthalpies and free energies $\left(\Delta H_{\mathrm{ads}, \mathrm{CO}}\right.$ and $\Delta G_{\mathrm{ads}, \mathrm{CO}}$ (at 1 bar) without dispersion corrections) on low-index terraces of the $\mathrm{Ru}_{218}$ particles at $1.04 \mathrm{CO} * \mathrm{ML}$ coverages are -46 $\mathrm{kJ} \mathrm{mol}^{-1}$ and $+36 \mathrm{~kJ} \mathrm{~mol}^{-1}$ (at $500 \mathrm{~K}$ ), respectively (Fig 2). The positive $\Delta G_{\text {ads,CO values would preclude }}$ $\mathrm{CO}^{*}$ adsorption at these coverages even at the high CO pressures of FTS ( 10 bar CO). These positive adsorption free energies reflect strong $\mathrm{CO}_{-} \mathrm{CO}^{*}$ repulsions, which are depicted visually in Figure 2 by the overlapping van der Waals radii on such crowded surfaces.

Figure 2. Calculated structures for $\boldsymbol{A}$ ) $\mathrm{CO}^{*}$-covered $\mathrm{Ru}_{218}$ particles and $\boldsymbol{B}$ ) vacancies at the center of the (111) terrace of $\mathrm{Ru}_{218}$ particles with views (on right) illustrating the crowded nature of these surfaces by displaying atoms with their van der Waals radii. $\mathrm{O}-\mathrm{O}$ bond distances between neighboring $\mathrm{CO}^{*}$ adsorbates are given in $\mathrm{pm}$. Differential adsorption enthalpies $\left(\Delta H_{\mathrm{ads}, \mathrm{CO}}, \mathrm{kJ}^{-1}{ }^{-1}\right)$, entropies $\left(\Delta S_{\mathrm{ads}, \mathrm{CO}}, \mathrm{J}\right.$ $\left.\mathrm{mol}^{-1} \mathrm{~K}^{-1}\right)$, and free energies $\left(\Delta G_{\mathrm{ads}, \mathrm{CO}}, \mathrm{kJ} \mathrm{mol}^{-1}\right)$ for $\mathrm{CO}^{*}$ are shown with (D3(NMI)) and without (RPBE) dispersion corrections.

These DFT-derived energies, however, neglect dispersive $\mathrm{CO} *-\mathrm{CO} *$ interactions and thus underestimate attractive induced dipole interactions between $\mathrm{CO}^{*}$ adsorbates, which, if included, stabilize CO* species. These attractive forces are considered here by using empirical (DFT-D3) [38,39] and semi-empirical (optB86b-vdW [36] and vdW-DF2 [37] exchange correlation functionals) methods. These methods substantially lower the $\Delta H_{\mathrm{ads}, \mathrm{CO}}$ and $\Delta G_{\mathrm{ads}, \mathrm{CO}}$ values (by 21-124 $\mathrm{kJ} \mathrm{mol}^{-1}$ ) relative to those from RPBE methods on surfaces with 1.044 ML CO*, but do not detectably influence adsorption entropies ( $\Delta S_{\text {ads,Co; }}$ Table 1). DFT-D3 methods give the strongest stabilization (decreasing both $\Delta H_{\text {ads,CO }}$ and $\Delta G_{\text {ads,CO }}$ by $123 \mathrm{~kJ} \mathrm{~mol}^{-1}$ ); while this empirical method can effectively model non-covalent interactions between gas-phase molecules [38,39], it has not been parametrized for the interactions between adsorbates and surface Ru atoms. 
Therefore, we include only dispersive interactions among co-adsorbates (NMI); RPBE-D3(NMI) gives $\Delta H_{\text {ads,Co }}$ and $\Delta G_{\text {ads,Co }}$ values of $-106 \mathrm{~kJ} \mathrm{~mol}^{-1}$ and $-23 \mathrm{~kJ} \mathrm{~mol}^{-1}$ at $500 \mathrm{~K}$, which are well within the range given by other DFT methods such as PW-91/USPP and PBE/PAW methods used elsewhere [12-15, 20], but are derived from methods which do not 'overbind' CO* at low-coverages as PW-91 and PBE approaches do (Table 1) $[35,48,49]$. Also, the $\Delta H_{\text {ads,Co }}$ and $\Delta G_{\text {ads,CO values from RPBE-D3(NMI) }}$ are consistent with the high $\mathrm{CO}^{*}$ coverages detected by infrared spectroscopy [8,9,41], isotopic switch experiments [4], kinetic data [5-7] at the conditions of FTS catalysis, as further discussed in Section 2. All enthalpies and free energies henceforth include $E_{d}$ values estimated by D3(NMI) methods, using Equations 3 and 4 in Section 2, and all calculations are carried out within these dense monolayers on $\mathrm{Ru}_{218}$ particles (1.044 ML CO*).

Table 1. Differential adsorption enthalpies $\left(\mathrm{kJ} \mathrm{mol}^{-1}\right)$, Gibbs free energies $\left(\mathrm{kJ} \mathrm{mol}^{-1}\right)$, and entropies $\left(\mathrm{J} \mathrm{mol}^{-1} \mathrm{~K}^{-1}\right)$ for $\mathrm{CO}^{*}$ on bare and $\mathrm{CO}^{*}$-saturated $(1.044 \mathrm{ML})$ low-index terraces of $\mathrm{Ru}_{218}$ particles calculated using different functionals.

\begin{tabular}{llcccccc}
\hline & & \multicolumn{3}{c}{$0.004 \mathrm{ML} \mathrm{CO}^{*} \mathrm{a}$} & \multicolumn{3}{c}{$1.044 \mathrm{ML} \mathrm{CO}^{*} \mathrm{a}^{\circ}$} \\
\multicolumn{1}{c}{ Functional } & Potentials & $\begin{array}{c}\Delta H \\
\mathrm{~kJ} \mathrm{~mol}^{-1}\end{array}$ & $\begin{array}{c}\Delta G \\
\mathrm{~kJ} \mathrm{~mol}^{-1}\end{array}$ & $\begin{array}{c}\Delta S \\
\mathrm{~J} \mathrm{~mol}^{-1} \mathrm{~K}^{-1}\end{array}$ & $\begin{array}{c}\Delta H \\
\mathrm{~kJ} \mathrm{~mol}^{-1}\end{array}$ & $\begin{array}{c}\Delta G \\
\mathrm{~kJ} \mathrm{~mol}^{-1}\end{array}$ & $\begin{array}{c}\Delta S \\
\mathrm{~J} \mathrm{~mol}^{-1} \mathrm{~K}^{-1}\end{array}$ \\
\hline RPBE & PAW & -151 & -79 & -144 & -46 & 36 & -165 \\
RPBE-D3(NMI) & PAW & -151 & -79 & -144 & -104 & -22 & -165 \\
RPBE-D3 & PAW & -193 & -121 & -144 & -169 & -87 & -165 \\
optB86b-vdW & PAW & -191 & -120 & -142 & -138 & -55 & -165 \\
vdW-DF2 & PAW & -141 & -70 & -142 & -67 & 13 & -160 \\
PBE & PAW & -175 & -104 & -142 & -126 & -45 & -163 \\
PW-91 & USPP & -178 & -100 & -155 & -96 & -18 & -156 \\
\hline
\end{tabular}

${ }^{\mathrm{a}}$ Coverages calculated based on 1 and $284 \mathrm{CO}^{*}$ species on full $\mathrm{Ru}_{586}$ nanoparticle cluster model.

\subsection{Chain Initiation Processes on $\mathrm{CO}^{*}$-Covered Surfaces}

We examine here how the presence of hydrocarbon chains disrupts these $\mathrm{CO}^{*}$ monolayers and, in doing so, influences $\mathrm{H}^{*}$-assisted $\mathrm{CO}^{*}$ activation transition states. $\mathrm{H}$-assisted $\mathrm{CO}^{*}$ activation requires quasi-equilibrated steps that form vacancies (via $\mathrm{CO}^{*}$ desorption, reverse of Step 1 in Scheme 1), $\mathrm{CH}^{*} \mathrm{O}^{*}$ (via $\mathrm{H}$-addition to $\mathrm{CO}^{*}$, Step 3) and $\mathrm{CH}^{*} \mathrm{OH}^{*}$ (via irreversible $\mathrm{H}$-addition to $\mathrm{CH}^{*} \mathrm{O}^{*}$, Step 4), which dissociate to $\mathrm{CH}^{*}$ and $\mathrm{OH}^{*}$ (Step 5) that end up ultimately removed as part of a chain and $\mathrm{H}_{2} \mathrm{O}$ products, respectively (Scheme 1). $\mathrm{H}_{2}$ dissociation (Step 2) requires vacant metal atoms for its transition state, but at equilibrium, chemisorbed $\mathrm{H}$-atoms (denoted as $\mathrm{H}^{\prime}$ ) reside at three-fold sites within the dense $\mathrm{CO}^{*}$ adlayer and do not displace co-adsorbed $\mathrm{CO}^{*}$. The presence of $\mathrm{H}^{\prime}$ at a three-fold site vicinal to 


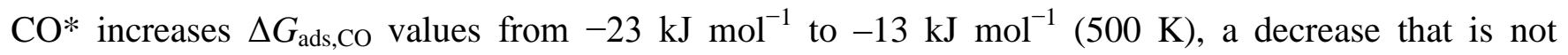
sufficient to prevent $\mathrm{CO}^{*}$ adsorption at such sites at the $\mathrm{CO}$ pressures typical of FTS (10 bar CO).

The inability of $\mathrm{H}^{\prime}$ to displace $\mathrm{CO}^{*}$ at low $\mathrm{H}^{\prime}$ coverages is reflected in IR studies $[6,8,9,41]$ that show $\mathrm{CO}^{*}$ peak intensities that are independent of $\mathrm{H}^{\prime}$ coverage. This is also consistent with large free energies for dissociative $\mathrm{H}_{2}$ chemisorption $\left(\sim 40 \mathrm{~kJ} \mathrm{~mol}^{-1}\right)$ and low barriers for associative $\mathrm{H}^{\prime}$ desorption $(\sim 20 \mathrm{~kJ}$ $\mathrm{mol}^{-1}$ ) which indicate quasi-equilibrated hydrogen adsorption. The low coverage of $\mathrm{H}^{\prime}$ is also supported by a range of other kinetic studies that show FTS rates that are linearly proportional to $\mathrm{H}_{2}$ pressure at all relevant $\mathrm{H}_{2}$ pressures $[2,5-8,10]$.

$$
\begin{aligned}
\mathrm{CO}+* & \rightleftharpoons \mathrm{CO}^{*} \\
\mathrm{H}_{2}+* & \rightleftharpoons 2 \mathrm{H}^{\prime}+* \\
\mathrm{CO}^{*}+*+\mathrm{H}^{\prime} & \rightleftharpoons \mathrm{HC}^{*} \mathrm{O}^{*} \\
\mathrm{HC}^{*} \mathrm{O}^{*}+\mathrm{H}^{\prime} & \longrightarrow \mathrm{CH}^{*} \mathrm{OH}^{*} \\
\mathrm{CH}^{*} \mathrm{OH}^{*} & \longrightarrow \mathrm{CH}^{*}+\mathrm{OH}^{*} \\
\mathrm{CH}^{*}+\mathrm{OH}^{*}+\mathrm{H}^{\prime} & \longrightarrow \mathrm{CH}^{*}+\mathrm{H}_{2} \mathrm{O}+*
\end{aligned}
$$

Scheme 1. Mechanism for $\mathrm{H}$-assisted $\mathrm{CO}^{*}$ activation via $\mathrm{CH}^{*} \mathrm{OH}^{*}$ intermediates, where $*$ indicates a site which $\mathrm{CO}^{*}$ can occupy and ' indicates a three-fold site in which $\mathrm{H}^{\prime}$ can bind without concomitant $\mathrm{CO}^{*}$ desorption.

$\mathrm{H}^{*}$-assisted $\mathrm{CO}^{*}$ activation routes (Scheme 1) lead to a FTS rate equation consistent with reported rate data $[2,5-8,10]$ :

$$
r=\frac{\gamma K_{\mathrm{CO}}(\mathrm{CO})\left(\mathrm{H}_{2}\right)}{\left[1+K_{\mathrm{CO}}(\mathrm{CO})\right]^{2}}
$$

where the $\mathrm{K}_{\mathrm{CO}}$ represents the adsorption constants for $\mathrm{CO}$ (Step 1 in Scheme 1). In the context of the elementary steps depicted in Scheme 1, the value of $\gamma$ is:

$$
\gamma=K_{\mathrm{H}_{2}} K_{\mathrm{HCO}} k_{\mathrm{HCOH}}
$$


where $K_{\mathrm{H} 2}$ is the adsorption constant for $\mathrm{H}_{2}$ (Step 2), $K_{\mathrm{HCO}}$ is the $\mathrm{CH}^{*} \mathrm{O} *$ formation equilibrium constant (Step 3) and $k_{\mathrm{HCOH}}$ is the rate constant for $\mathrm{CH}^{*} \mathrm{OH}^{*}$ formation (Step 4). High $\mathrm{CO}^{*}$ coverages prevail at FTS conditions, resulting in $\mathrm{K}_{\mathrm{CO}}(\mathrm{CO}) \gg 1$ and:

$$
r=\frac{\gamma\left(\mathrm{H}_{2}\right)}{K_{\mathrm{CO}}(\mathrm{CO})}
$$

where $\gamma$ and $\mathrm{K}_{\mathrm{CO}}$ can be written in terms of free energy differences as:

$$
\frac{\gamma}{K_{C O}^{2}}=\frac{k_{B} T}{h} e^{\left(-\frac{\Delta G^{\ddagger}}{R T}\right)}
$$

with

$$
\begin{aligned}
\Delta G^{\neq} & =\Delta G_{\gamma}^{\neq}-\Delta G_{a d s, C o} \\
\Delta G_{\gamma}^{\neq} & =\Delta G_{a c t, 4}+\Delta G_{r x n, 3}+\Delta G_{a d s, H_{2}}
\end{aligned}
$$

These equations can be rewritten in terms of the free energies of $\mathrm{CH}^{*} \mathrm{O}^{*}-\mathrm{H} \neq$ and $\mathrm{CO}^{*}$ and of gaseous species:

$$
\begin{aligned}
& \Delta G_{\gamma}^{*}=G\left[\mathrm{CH}^{*} \mathrm{O}-\mathrm{H}^{*} \neq\right]-G\left[\mathrm{H}_{2}\right]-G\left[\mathrm{CO}^{*}\right]-G\left[^{*}\right] \\
& \Delta G_{a d s, C O}=G\left[\mathrm{CO}^{*}\right]-G\left[{ }^{*}\right]-G[\mathrm{CO}]
\end{aligned}
$$

$\Delta \mathrm{G}_{\gamma}^{\ddagger}$ thus represents the free energy of formation of the $\mathrm{CH}^{*} \mathrm{O}-\mathrm{H}^{*} \neq$ transition state from a surface with a single vacancy (along with the stoichiometric amounts of gaseous $\mathrm{H}_{2}$ ).

Figure 3 depicts the DFT-derived reaction coordinate with reaction and activation enthalpies and free energies for $\mathrm{H}$-assisted $\mathrm{CO}^{*}$-activation routes. $\mathrm{CO} *$ desorption forms a vacant site (reverse of Step 1) with $-\Delta H_{\text {ads,CO }}$ and $-\Delta G_{\text {ads,CO }}$ values of 104 and $22 \mathrm{~kJ} \mathrm{~mol}^{-1}$, respectively. Hydrogen is activated at this vacancy (Step 3 ) to form $2 \mathrm{H}^{\prime}$ species, one of which reacts with $\mathrm{CO}^{*}$ to form $\mathrm{CH}^{*} \mathrm{O}^{*}$ (which occupies two sites on the catalyst surface, Step 3) in an endothermic step $\left(\Delta H_{\mathrm{rxn}}=+79 \mathrm{~kJ} \mathrm{~mol}^{-1}, \Delta G_{\mathrm{rxn}}=\right.$ $+82 \mathrm{~kJ} \mathrm{~mol}^{-1}$ ). The barriers for $\mathrm{CH}^{*} \mathrm{O}^{*}$ decomposition to $\mathrm{H}^{\prime}$ and $\mathrm{CO}^{*}$ (reverse of Step 2, Scheme 1) are smaller (by $45 \mathrm{~kJ} \mathrm{~mol}^{-1}$ in enthalpy and by $78 \mathrm{~kJ} \mathrm{~mol}^{-1}$ in free energy) than for $\mathrm{CH}^{*} \mathrm{O}^{*}$ reactions with $\mathrm{H}^{*}$ to form $\mathrm{CH}^{*} \mathrm{OH}^{*}$ (Step 4), thus rendering Step 3 quasi-equilibrated. The formation of $\mathrm{CH}_{2} \mathrm{O}$ from $\mathrm{CH}^{*} \mathrm{O}^{*}$ and $\mathrm{H}^{\prime}$ has $\Delta G \neq$ of $226 \mathrm{~kJ} \mathrm{~mol}^{-1}$, slightly lower than that to form $\mathrm{CH}^{*} \mathrm{OH}^{*}$. The reverse free 
energy barrier (158 kJ mol${ }^{-1}$ ) for $\mathrm{CH}_{2} \mathrm{O}$ decomposition indicates that $\mathrm{CH}_{2} \mathrm{O}$ is likely in equilibrium with $\mathrm{CO}$ and $\mathrm{H}_{2}$. The equilibrium concentration of $\mathrm{CH}_{2} \mathrm{O}$ will be very low at FTS conditions as the equilibrium constant is $9 \times 10^{-5}$, consistent with the presence of $\mathrm{CH}_{2} \mathrm{O}$ as a trace product during FTS. The transition states for $\mathrm{CH}^{*} \mathrm{OH}^{*}$ formation and for its dissociation (to $\mathrm{CH}^{*}$ and $\mathrm{OH}^{*}$ ) exhibit similar formation enthalpies ( $\Delta H \neq=234$ and $233 \mathrm{~kJ} \mathrm{~mol}^{-1}$, respectively) and free energies $\left(\Delta G \neq\right.$ of $228 \mathrm{~kJ} \mathrm{~mol}^{-1}$ and $225 \mathrm{~kJ} \mathrm{~mol}^{-1}$, respectively). The similarities in these barriers make it impossible to determine the reversibility of $\mathrm{CH}^{*} \mathrm{OH}^{*}$ formation. These two transition states are, however, kineticallyindistinguishable and lead to the same rate equation because of their similar stoichiometry; thus, the reversibility of $\mathrm{CH}^{*} \mathrm{OH}^{*}$ formation does not affect the form of the observed rate equation (Eq. 8), but only the mechanistic interpretation of $\gamma \cdot \mathrm{CH}^{*} \mathrm{OH}^{*}$ dissociation forms $\mathrm{CH}^{*}$ and $\mathrm{OH}^{*}$ and the latter reacts with $\mathrm{H}^{\prime}$ to form $\mathrm{H}_{2} \mathrm{O}$, which desorbs from the surface creating a vacant site for $\mathrm{CO}^{*}$ to adsorb. The $\Delta \mathrm{G} \neq$ for $\mathrm{CH}^{*} \mathrm{O}-\mathrm{H}^{*}$ formation is $228 \mathrm{~kJ} \mathrm{~mol}^{-1}$, which comprises a $\Delta G_{\gamma}$ of $206 \mathrm{~kJ} \mathrm{~mol}^{-1}$ and a $\Delta G_{\text {ads,CO }}$ value $-22 \mathrm{~kJ} \mathrm{~mol}^{-1}$ (Fig. 3B). The overall reaction that converts $\mathrm{CO}^{*}$ and $1.5 \mathrm{H}_{2}$ to $\mathrm{CH}^{*}$ and $\mathrm{H}_{2} \mathrm{O}$ is exothermic $\left(\Delta H_{\mathrm{rxn}}=-23\right.$ and $\Delta G_{\mathrm{rxn}}=-2 \mathrm{~kJ} \mathrm{~mol}^{-1}$, Fig. 4) and once a chain has been initiated (via $\mathrm{CH}^{*}$ formation), it can either terminate to form undesired $\mathrm{CH}_{4}$ or grow via $\mathrm{CO}_{-}$or $\mathrm{CH}_{\mathrm{x}}{ }^{*}$-insertion mechanisms.

Figure 3. A) Enthalpy and B) free energy diagrams for $\mathrm{H}^{*}$-assisted $\mathrm{CO}$ activation (chain initiation) on $\mathrm{Ru}_{218}$ nanoparticles at $1.05 \mathrm{ML} \mathrm{CO} *$. Effective enthalpy and free energy barriers $\left(\Delta H^{\ddagger}\right.$ and $\Delta G^{\ddagger}$ (Eq. 9)) reflect the $\Delta H$ and $\Delta G$ to form transition states from $\mathrm{CO}^{*}$-covered surfaces and stoichiometric amounts of $\mathrm{H}_{2}(g)$ and are shown for each transition state. $\Delta H_{\gamma}^{\dagger}$ and $\Delta G_{\gamma}^{\dagger}$ (Eq. 10) represent the enthalpy and free energies to form the $\mathrm{CH}^{*} \mathrm{O}-\mathrm{H}^{*} \neq$ from $\mathrm{CO}^{*}$ and a vicinal vacancy (*). Electronic energy differences and zero-point corrections are shown in the SI (Table S1).

Figure 4. DFT-derived structures for A) $\mathrm{CH}^{*} \mathrm{O}^{*}+\mathrm{H}^{\prime}$, B) $\mathrm{CH}^{*} \mathrm{O}^{*}-\mathrm{H} \neq$, C) $\mathrm{CH}^{*} \mathrm{OH}^{*}$, D) $\mathrm{CH}^{*}+$ $\mathrm{OH}^{*}$, E) $\mathrm{CH}^{*}+\mathrm{OH}^{*}-\mathrm{H} \neq$, and $\left.\mathbf{F}\right) \mathrm{CH}^{*}+\mathrm{CO}^{*}$ along with enthalpies, entropies and free energies to form those states (along with stoichiometric amounts of gas-phase species) from a $\mathrm{CO}^{*}$-covered surface. Top pictures omit spectating $\mathrm{CO}^{*}$ species for clarity and have bond distances labeled in $\mathrm{pm}$. Structures for all states in Fig. 3 shown in the SI (Figs. S1-S5). 


\subsection{The Formation of Carbon-Carbon Bonds via $\mathrm{CH}_{x}{ }^{*}$-Insertion}

The dearth of chains on working surfaces and their fast growth [4] may reflect direct $\mathrm{CO}^{*}$ insertion, which we consider in a later study. Alternatively, $\mathrm{CH}_{\mathrm{x}} *$ monomers or growing $\mathrm{RCH}_{\mathrm{x}} *$ chains may decrease the free energy of the transition state for $\mathrm{H}^{\prime}$ addition to $\mathrm{CH}^{*} \mathrm{O} *$ (referenced to its relevant precursor), specifically by avoiding the need to remove an additional $\mathrm{CO}^{*}$ to form this transition state.

The ratio of the rate of chain growth $(\mathrm{C}-\mathrm{C}$ bond formation) to chain initiation ( $\mathrm{CO} *$ activation) is simply given by:

$$
\frac{r_{\text {growth }}}{r_{\text {init }}}=\bar{n}-1
$$

where $(\bar{n})$ represents the average number of C-atoms in the products formed; this value is typically $>10$ for practical Fischer-Tropsch synthesis. The rate of chain initiation is given by Eq. 5 in which $\gamma$ is the lumped rate constant for

$$
\mathrm{CO}^{*}+*+\mathrm{H}_{2} \rightarrow \mathrm{CH}^{*} \mathrm{O} *-\mathrm{H} \neq
$$

which ultimately leads to $\mathrm{CH}^{*}$ species on the catalyst surface (Step 5 in Scheme 1). Once two $\mathrm{CH}^{*}$ species are co-adsorbed, they can react to form a new $\mathrm{C}-\mathrm{C}$ bond:

$$
\mathrm{CH}^{*}+\mathrm{CH}^{*} \rightarrow \mathrm{CH}^{*} \mathrm{CH}^{*}
$$

The intrinsic activation enthalpies and free energies $\left(\Delta H_{\text {act }}\right.$ and $\Delta G_{\text {act }}$ of 88 and $94 \mathrm{~kJ} \mathrm{~mol}^{-1}$, respectively, Fig. 5) are much smaller than the effective activation enthalpies and free energies for $\mathrm{CO}^{*}$ activation (230 and $235 \mathrm{~kJ} \mathrm{~mol}^{-1}$ ), indicating that $\mathrm{CH}_{\mathrm{x}}{ }^{*}$-insertion reactions are limited by the high activation free energies for forming vicinal $\mathrm{CH}_{\mathrm{x}}{ }^{*}$ species, rather than the activation free energies for $\mathrm{C}-\mathrm{C}$ bond formation.

Figure 5. DFT-derived structures for the A) $\mathrm{CH}^{*}+\mathrm{CH}^{\prime}$, B) $\mathrm{CH}^{*}-\mathrm{CH}^{\prime} \neq$, and $\mathbf{C}$ ) $\mathrm{CHCH}^{*}$ along with enthalpies, entropies and free energies to form the transition and product states from the reactant precursor. Top pictures omit spectating $\mathrm{CO}^{*}$ species for clarity and have bond distances labeled in $\mathrm{pm}$.

Alternative $\mathrm{CH}_{\mathrm{x}}$ *-insertion steps and the $\mathrm{H}^{\prime}$-addition steps which ultimately form olefin and paraffin products are currently being examined using the same theoretical approaches utilized herein as part of a separate study. 


\subsection{CO* Activation on Dense CO* Monolayers Disrupted by Growing Chains}

The rate of chain-growth is not limited by $\mathrm{C}-\mathrm{C}$ bond formation, as these steps occur readily among vicinal hydrocarbon chains and $\mathrm{CH}_{\mathrm{x}} *$ monomers, as shown in Section 3.3. Instead, growth rates are limited by $\mathrm{CO}^{*}$ activation (to form $\mathrm{CH}_{\mathrm{x}} *$ monomers) at sites vicinal to growing chains (of length $n$ )

$$
\mathrm{CO} *+\mathrm{C}_{n} \mathrm{H}_{2 n-1} *+\mathrm{H}_{2} \rightarrow \mathrm{CH}^{*} \mathrm{O}^{*}-\mathrm{H} \neq+\mathrm{C}_{n} \mathrm{H}_{2 n-1}{ }^{\prime}
$$

where the vicinal chain (shown as $\mathrm{CH}^{*}$ in Fig. $4 \mathrm{~F}$ ) and $\mathrm{CH}^{*} \mathrm{O}^{*}-\mathrm{H} \neq$ transition states (Fig. 4B) share a metal atom site on the catalyst surface (labeled ' $\mathrm{Y}$ ' in Fig. 4). The same sequence of elementary steps (Steps 2-6 in Scheme 1) leads to $\mathrm{CH}^{*} \mathrm{O}^{*}-\mathrm{H} \neq$ formation in Eqs. 14 and 16. The rate of chain growth (limited by Eq. 15) can thus be written as:

$$
r_{\text {growth }}=\frac{\gamma_{n} K_{C O}(\mathrm{CO})\left(\mathrm{H}_{2}\right)\left[\mathrm{C}_{n}^{*}\right]}{1+K_{C O}(\mathrm{CO})} \quad \frac{r_{\text {growth }}}{r_{\text {init }}\left[C_{n}^{*}\right]}=\frac{\gamma_{n}\left[1+K_{C O}(\mathrm{CO})\right]}{\gamma_{0}}
$$

where $\left[\mathrm{C}_{n}{ }^{*}\right]$ is the concentration of chains with length $n$. For each individual chain, Eqs. 5 and 17 can be rewritten as:

$$
\frac{r_{\text {growth }}}{r_{\text {init }}\left[C_{n}^{*}\right]}=\frac{\gamma_{n} K_{\mathrm{CO}}(\mathrm{CO})}{\gamma_{0}} \quad r=\frac{\gamma K_{\mathrm{CO}}(\mathrm{CO})\left(\mathrm{H}_{2}\right)}{\left[1+K_{\mathrm{CO}}(\mathrm{CO})\right]^{2}}
$$

at high $\mathrm{CO}$ pressures $\left(\mathrm{K}_{\mathrm{CO}}(\mathrm{CO}) \gg 1\right)$, where $\gamma_{0}$ and $\gamma_{n}$ are the lumped rate constants for the steps in Eqs. 14 and 16 . These $\gamma$ parameters can be written in terms of free energy differences:

$$
\gamma_{i}=\frac{k_{B} T}{h} \exp \left(\frac{-\Delta G_{\gamma i}}{R T}\right)
$$

which can be rewritten in terms of the free energies of the $\mathrm{CH}^{*} \mathrm{O}^{*}-\mathrm{H} \neq, \mathrm{CO}^{*}$, and gas-phase species:

$$
\begin{aligned}
\Delta G_{\gamma 0}^{*} & =G\left[\mathrm{CH}^{*} \mathrm{O}-\mathrm{H}^{*}\right]-G\left[\mathrm{H}_{2}\right]-G\left[\mathrm{CO}^{*}\right]-G\left[{ }^{*}\right] \\
\Delta G_{\gamma n}^{*} & =G\left[\mathrm{CH}^{*} \mathrm{O}-\mathrm{H}^{*}\right]-G\left[\mathrm{H}_{2}\right]-G\left[\mathrm{CO}^{*}\right]-G\left[C_{n}{ }^{*}\right]
\end{aligned}
$$

These free energies are calculated from DFT with $\left(\Delta \mathrm{G}_{\gamma n}{ }^{\dagger}\right)$ and without $\left(\Delta \mathrm{G}_{\gamma 0}{ }^{\dagger}\right)$ a vicinal hydrocarbon chain.

First, we examine the activation of a $\mathrm{CO}^{*}$ vicinal to a bound $\mathrm{CH}^{*}$. Figure $4 \mathrm{~F}$ shows that $\mathrm{CH}^{*}$ binds to a three-fold site, preserving space in the $\mathrm{CO}^{*}$-monolayer on the catalyst surface directly above metal atom ' $\mathrm{Y}$ '. CO* adsorption at this site $(\mathrm{Y})$ has a large positive $\Delta G_{\mathrm{ads}, \mathrm{CO}}\left(+21 \mathrm{~kJ} \mathrm{~mol}^{-1}\right)$, indicating that CO* adsorption is unlikely to occur, even at the typical CO pressures (10 bar) in FTS. This space in the 
$\mathrm{CO}^{*}$-monolayer above metal atom $(\mathrm{Y})$, however, can accommodate the $\mathrm{CH}^{*} \mathrm{O} *-\mathrm{H} \neq$ transition state, as discussed in the next section. Figure 5 shows DFT-derived reaction and activation free energies for $\mathrm{H}$ assisted $\mathrm{CO}^{*}$ activation vicinal to $\mathrm{CH}^{*}$ and for the $\mathrm{H}$-assisted path within dense $\mathrm{CO}^{*}$ monolayers without the disruptions by $\mathrm{CH}^{*}$ species. The steps that initiate such chains within $\mathrm{CO}^{*}$ monolayers require $\mathrm{CO}^{*}$ desorption to create the space necessary to form and bind $\mathrm{CH}^{*} \mathrm{O} *-\mathrm{H} \neq$ transition state structures, as discussed in Section 3.2. In contrast, $\mathrm{CO}^{*}$ activation vicinal to a chain does not require $\mathrm{CO}^{*}$ desorption, as the chain effectively prevents $\mathrm{CO}^{*}$ adsorption at such nearby sites and preserves the vacancy. Except for the lack of this $\mathrm{CO}$ desorption requirement $\left(\Delta G_{\mathrm{des}, \mathrm{CO}}\left(+22 \mathrm{~kJ} \mathrm{~mol}^{-1}\right)\right)$, the chainassisted $\mathrm{CO}^{*}$ activation proceeds via the same elementary steps as those for chain initiation on dense $\mathrm{CO}^{*}$ monolayer surfaces (Steps 2-6 in Scheme 1). The free energy of activation to form $\mathrm{CH}^{*} \mathrm{O}^{*}-\mathrm{H}^{*}$ from $\mathrm{CO}^{*}$ and $\mathrm{H}_{2}$ with a co-adsorbed $\mathrm{CH}^{*}$ species $\left(\Delta \mathrm{G}_{\gamma 1}{ }^{\dagger}\right)$ is $204 \mathrm{~kJ} \mathrm{~mol}^{-1}$, whereas the same reaction vicinal to a vacancy results in a similar value $\left(\Delta \mathrm{G}_{\gamma 0}{ }^{\dagger}\right.$ of $\left.206 \mathrm{~kJ} \mathrm{~mol}^{-1}\right)$, leading to a decrease in the overall free energy barrier $\left(\Delta \mathrm{G}^{\star}\right)$ of $24 \mathrm{~kJ} \mathrm{~mol}^{-1}$ for $\mathrm{CH}^{*}$-assisted $\mathrm{CO}^{*}$ activation (Fig. 6). The small changes in $\Delta \mathrm{G}_{\gamma}{ }^{\dagger}$ with co-adsorbed $\mathrm{CH}^{*}\left(\Delta \mathrm{G}_{\gamma 1}{ }^{\dagger}\right)$ and without a co-adsorbed $\mathrm{CH}^{*}\left(\Delta \mathrm{G}_{\gamma 0}{ }^{\dagger}\right)$ indicate that lateral interactions between $\mathrm{CH}^{*} \mathrm{O}^{*}-\mathrm{H} \neq$ and $\mathrm{CH}^{*}$ are weak $\left(<3 \mathrm{~kJ} \mathrm{~mol}^{-1}\right)$ further demonstrated by similar $\mathrm{CH}^{*} \mathrm{O}^{*}-\mathrm{H} \neq$ geometries (Figs. 4B and 7B). The weak lateral interactions between $\mathrm{CH}^{*}$ and the $\mathrm{CH}^{*} \mathrm{O}^{*}-$ $\mathrm{H} \neq$ are unique to that reaction, as co-adsorbate interactions between $\mathrm{CH}^{*}$ and the transition states for forming both $\mathrm{CH}^{*} \mathrm{O}^{*}$ and $\mathrm{H}_{2} \mathrm{O}^{*}$ are significant, leading to similar $\Delta \mathrm{G} \neq$ values for those reactions during $\mathrm{CH}^{*}$-assisted and non-assisted paths. The rate of $\mathrm{CO}^{*}$ activation, however, is ultimately dependent on the stabilities of the $\mathrm{CH}^{*} \mathrm{O}^{*}-\mathrm{H} \neq$ transition state, making these other transition states (or their interactions with vicinal chains) irrelevant to rates of $\mathrm{CO}^{*}$ activation. The differences in the overall apparent activation energy for the non-assisted $\left(\Delta \mathrm{G}_{0}{ }^{\dagger}\right)(-24 \mathrm{~kJ} / \mathrm{mol})$ and the $\mathrm{CH}^{*}$-assisted $\left(\Delta \mathrm{G}_{1}{ }^{\star}\right)$ path $(+24 \mathrm{~kJ}$ $\left.\mathrm{mol}^{-1}\right)$ is predominantly due to the free energy required to desorb $\mathrm{CO}^{*}\left(\Delta G_{\mathrm{des}, \mathrm{CO}},+22 \mathrm{~kJ} \mathrm{~mol}^{-1}\right)$ to create the vacancy necessary to activate $\mathrm{CO}^{*}$ on the non-assisted surface.

Furthermore, the difference between $\Delta \mathrm{G}_{0}{ }^{\dagger}$ and $\Delta \mathrm{G}_{1}{ }^{\neq}$was also computed for the optB86b-vdW functional (with PAW potentials) and the PW-91 functional (with USPP pseudopotentials) in order to benchmark the novel RPBE-D3(NMI) method presented here against more widely-used methods. The PW-91 functional predicted a difference between $\Delta \mathrm{G}_{0}{ }^{\dagger}$ and $\Delta \mathrm{G}_{1}{ }^{\dagger}$ of $30 \mathrm{~kJ} \mathrm{~mol}^{-1}$ while the optB86b-vdW method predicted a difference of $38 \mathrm{~kJ} \mathrm{~mol}^{-1}$ (Table S1, SI) The positive differences in free energy barriers by these methods are consistent with the difference $\left(+24 \mathrm{~kJ} \mathrm{~mol}^{-1}\right)$ predicted by RPBED3(NMI), indicating that the conclusions herein are not dependent upon the choice of a unique 
functional. Furthermore, the differences between $\Delta \mathrm{G}_{0}{ }^{\dagger}$ and $\Delta \mathrm{G}_{1}{ }^{\ddagger}$ for all three methods $\left(24 \mathrm{~kJ} \mathrm{~mol}^{-1}, 30\right.$ $\mathrm{kJ} \mathrm{mol}^{-1}, 38 \mathrm{~kJ} \mathrm{~mol}^{-1}$ for D3(NMI), PW-91, and optB86b-vdW) are similar to the $\Delta G_{\mathrm{des}, \mathrm{Co}}$ predicted by those methods (22 $\mathrm{kJ} \mathrm{mol}^{-1}, 18 \mathrm{~kJ} \mathrm{~mol}^{-1}$, and $55 \mathrm{~kJ} \mathrm{~mol}^{-1}$ for D3(NMI), PW-91, and optB86b-vdW) as shown in Figure S10 (SI). This relationship between $\left(\Delta \mathrm{G}_{0}{ }^{\dagger}\right.$ and $\left.\Delta \mathrm{G}_{1}{ }^{\dagger}\right)$ and $\Delta G_{\text {des,Co indicates that DFT }}$ methods which predict positive free energies for desorbing $\mathrm{CO}^{*}$ (such as the widely-used PBE method, Table 1) will also predict positive differences between $\Delta \mathrm{G}_{0}{ }^{\dagger}$ and $\Delta \mathrm{G}_{1}{ }^{\dagger}$, leading to conclusions consistent with those presented herein for the novel D3(NMI) approach.

Figure 6. Comparison of the free energy diagrams for the $\mathrm{H}^{*}$-assisted $\mathrm{CO}^{*}$ activation without a vicinal chain (black curve) and the $\mathrm{CH}^{*}$ promoted $\mathrm{H}^{*}$-assisted $\mathrm{CO}^{*}$ activation (green curve) on $\mathrm{Ru}$ nanoparticles at $1.05 \mathrm{ML} \mathrm{CO*}$. Effective free energy barriers $\left(\Delta G^{\star}\right)$ are the $\Delta G$ to form transition states from their respective 'reference' states and stoichiometric amounts of $\mathrm{H}_{2}$ and are shown for each transition state. Labels for each state are simplified for clarity, but full labels can be seen in Figure 3. Enthalpy differences (along with electronic energies and zero-point corrections) are shown in the SI (Tables S1-S2).

Figure 7. DFT-calculated structures for A) $\mathrm{CH}^{*} \mathrm{O}^{*}+\mathrm{H}^{\prime}+\mathrm{CH}^{\prime}$, B) $\mathrm{CH}^{*} \mathrm{O} *-\mathrm{H} \neq+\mathrm{CH}^{\prime}$, C) $\mathrm{CH}^{*} \mathrm{OH}^{*}$ $+\mathrm{CH}^{\prime}$, D) $\mathrm{CH}^{*}+\mathrm{OH}^{*}+\mathrm{CH}^{\prime}$, E) $\mathrm{CH}^{*}+\mathrm{OH}^{*}-\mathrm{H} \neq+\mathrm{CH}^{\prime}$, and $\left.\mathbf{F}\right) \mathrm{CH}^{*}+\mathrm{CO}^{*}+\mathrm{CH}^{\prime}$ along with enthalpies, entropies and free energies to form those states (along with stoichiometric amounts of gasphase species) from $\mathrm{CO}^{*}+\mathrm{CH}^{*}$ (Fig. 4F). Top pictures omit spectating $\mathrm{CO}^{*}$ species for clarity and have bond distances labeled in pm. Structures for all states in Fig. 6 shown in the SI (Figs. S6-S9).

To assess the effects of hydrocarbon chain length on the free energy barrier to form the $\mathrm{CH}^{*} \mathrm{O}^{*}-\mathrm{H}^{\ddagger}$ transition state vicinal to a growing chain $\left(\Delta \mathrm{G}_{\gamma i}{ }^{\ddagger}, i>0\right), \mathrm{CO}^{*}$ activation was also examined vicinal to $\mathrm{CH}_{3} \mathrm{C}^{*}, \mathrm{C}_{2} \mathrm{H}_{5} \mathrm{C}^{*}$, and $\mathrm{C}_{3} \mathrm{H}_{7} \mathrm{C}^{*}\left(\mathrm{CO}^{*}\right.$ activation vicinal to alkylidene and alkylidyne chains is discussed in Section 3.4). The average $\Delta G_{\gamma i}{ }^{\neq}$for $\mathrm{CH}^{*} \mathrm{O}^{*}-\mathrm{H} \neq$ formation vicinal to an alkylidyne chain $\left(\mathrm{C}_{1}-\mathrm{C}_{4}\right)$ is $213 \mathrm{~kJ} \mathrm{~mol}^{-1}$, as shown in Fig. 8B, slightly higher than for $\mathrm{CH}^{*}$ species $\left(\Delta G_{\gamma 1}{ }^{\dagger}=206 \mathrm{~kJ} \mathrm{~mol}^{-1}\right)$, leading to the ratio of lumped rate constants for $\mathrm{CO}^{*}$ activation $\left(\gamma_{\mathrm{n}} / \gamma_{0}\right.$ in Eq. 18) of $\sim 0.2$ at $500 \mathrm{~K}$, which then simplifies to: 


$$
\frac{r_{\text {growth }}}{r_{\text {init }}\left[C_{n}^{*}\right]}=0.2 K_{C O}(C O)=0.2 \exp \left(\frac{-\Delta G_{\mathrm{ads}, \mathrm{CO}}}{R T}\right)(C O)
$$

at high $\mathrm{CO}^{*}$ coverages $\left(K_{\mathrm{CO}}(\mathrm{CO})>>1\right)$ inferred from experiments or estimated from DFT $\left(\Delta G_{\mathrm{ads}, \mathrm{CO}}=\right.$ $-22 \mathrm{~kJ} \mathrm{~mol}^{-1}$, Eq. 12), resulting in large ratios of chain growth to chain initiation via CO* activation enhanced by vicinal hydrocarbon chains.

Figure 8. $\boldsymbol{A})$ Enthalpy and $\boldsymbol{B})$ Free energy differences $(500 \mathrm{~K})$ for forming $\mathrm{CH}^{*} \mathrm{O} *-\mathrm{H} \neq$ from $\mathrm{CO}^{*}$ vicinal to a $\mathrm{CO}^{*}\left(\Delta H_{\gamma 1}\right.$ and $\left.\Delta G_{\gamma 1}\right)$ and hydrocarbon chains $\left(\mathrm{C}_{n} \mathrm{H}_{2 n-1}{ }^{*}, \Delta H_{\gamma(n+1)}\right.$ and $\left.\Delta G_{\gamma(n+1)}, \mathrm{n}=1-4\right)$. CO* desorption energies $\left(-\Delta H_{\mathrm{ads}, \mathrm{CO}}=104 \mathrm{~kJ} \mathrm{~mol}^{-1}\right.$ and $\left.-\Delta G_{\mathrm{ads}, \mathrm{CO}}=23 \mathrm{~kJ} \mathrm{~mol}^{-1}\right)$ are also shown as it is required for forming $\mathrm{CH}^{*} \mathrm{O} *-\mathrm{H} \neq$ from two $\mathrm{CO}^{*}$ species on the surface (during initiation). The average $\Delta H_{\gamma n}$ and $\Delta G_{\gamma n}(\mathrm{n}=2-5)$ values (134 and $213 \mathrm{~kJ} \mathrm{~mol}^{-1}$, respectively) are shown by the dashed line. Tables containing energies for the full $\mathrm{H}$-assisted $\mathrm{CO}^{*}$ activation pathways vicinal to a $\mathrm{CO}^{*}, \mathrm{CH}^{*}, \mathrm{CH}_{3} \mathrm{C}^{*}$, $\mathrm{C}_{2} \mathrm{H}_{5} \mathrm{C}^{*}$, and $\mathrm{C}_{3} \mathrm{H}_{7} \mathrm{C}^{*}$ are shown in the SI (Tables S2-S6).

The ability of growing chains to promote the local activation of $\mathrm{CO}^{*}$ leads to a rate equation modified from Eq. 5 to reflect $\mathrm{CO}^{*}$ consumption vicinal to growing chains:

$$
r_{C O}=\frac{\gamma_{0} K_{C O}(\mathrm{CO})\left(\mathrm{H}_{2}\right)}{\left[1+K_{C O}(\mathrm{CO})\right]^{2}}\left(1+\alpha_{1} \sum_{n=1}^{\infty}\left(\frac{\gamma_{n}}{\gamma_{1}}\right) \prod_{i=1}^{n} \alpha_{i-1}\right)
$$

derived in the SI (by employing a pseudo-steady-state hypothesis on $\mathrm{C}_{1}{ }^{*}$, Eqs. S14-S26), where $\alpha$ is the chain growth probability:

$$
\alpha_{i}=\frac{r_{\text {growth }, i}}{r_{\text {growth }, i}+r_{\text {term }, i}}
$$

The summation term in Eq. 23 represents $\mathrm{CO}^{*}$-consumed in the propagation of a chain (rather than in its initiation). At FTS conditions, this term is thus much greater than 1 (since chains are longer than $\mathrm{C}_{10}$ on average), indicating that most $\mathrm{CO}^{*}$ is consumed at sites vicinal to growing chains, rather than on unperturbed $\mathrm{CO}^{*}$-covered surfaces as these chains are unable to migrate on $\mathrm{CO}^{*}$-covered surfaces. As a result, measured FTS activation barriers do not represent enthalpies of isolated CO* activation that initiated each chain $\left(234 \mathrm{~kJ} \mathrm{~mol}^{-1}\right.$, Fig. 3A), but those for $\mathrm{CO}^{*}$ activations vicinal to growing chains (average of $136 \mathrm{~kJ} \mathrm{~mol}^{-1}$, Fig. 8A), whose values are similar to reported measured activation barriers (100-150 kJ mol ${ }^{-1}$ ) on Co [7] and Ru [8] catalysts. 


\subsection{Relative Alkylidyne, Alkylidene, and Alkyl Coverages and their Kinetic Relevance}

The results in Section 3.3 confirm that alkylidyne $\left(\mathrm{C}_{n} \mathrm{H}_{2 n-1}{ }^{*}\right)$ species (e.g., $\mathrm{CH}^{*}, \mathrm{CH}_{3} \mathrm{C}^{*}, \mathrm{C}_{2} \mathrm{H}_{5} \mathrm{C}^{*}$ ) promote the activation of vicinal $\mathrm{CO}^{*}$ species on Ru surfaces by disrupting dense $\mathrm{CO} *$ adlayers and thus creating an activation space that avoids the need to desorb CO*. These surface alkylidyne are stable at high CO* coverages and do not decompose which is consistent with previous studies ${ }^{48}$ that show CO* block ethylidyne dehydrogenation paths and enhances its ability to react with other hydrocarbon surface intermediates. It seems plausible that other chemisorbed species, such as $\mathrm{C}^{*}$, alkylidenes $\left(\mathrm{C}_{n} \mathrm{H}_{2 n}{ }^{*}\right)$, or alkyls $\left(\mathrm{C}_{n} \mathrm{H}_{2 n+1} *\right)$ can also create such spaces and thus promote $\mathrm{CO}^{*}$ activation in their vicinity.

The ratio of the rates of $\mathrm{CO}^{*}$ activation vicinal to an alkylidene $\mathrm{r}_{\mathrm{CO}, \mathrm{CnH} 2 \mathrm{n}^{*}}$ ) or alkyl $\mathrm{r}_{\mathrm{CO}, \mathrm{CnH} 2 \mathrm{n}+1^{*}}$ ) chain to that at a location vicinal to an alkylidyne chain $\left(\mathrm{r}_{\left.\mathrm{CO}, \mathrm{CnH} 2 \mathrm{n}-1^{*}\right)}\right)$ are given by:

$$
\begin{aligned}
& \frac{r_{C O, C_{n} H_{2 n}^{*}}}{r_{C O, C_{n} H_{2 n-1}^{*}}}=\frac{\left[C_{n} H_{2 n}^{*}\right]}{\left[C_{n} H_{2 n-1}^{*}\right]} \exp \left(\frac{-\Delta G_{\gamma, C_{n} H_{2 n}^{*}}+\Delta G_{\gamma, C_{n} H_{2 n-1}^{*}}}{R T}\right) \\
& \frac{r_{C O, C_{n} H_{2 n+1}^{*}}}{r_{C O, C_{n} H_{2 n-1}^{*}}}=\frac{\left[C_{n} H_{2 n+1}^{*}\right]}{\left[C_{n} H_{2 n-1}^{*}\right]} \exp \left(\frac{-\Delta G_{\gamma, C_{n} H_{2 n+1}^{*}}+\Delta G_{\gamma, C_{n} H_{2 n-1}^{*}}}{R T}\right)
\end{aligned}
$$

respectively. These ratios depend in turn on the relative coverages of alkylidene or alkyl chains to that of alkylidynes and on the difference in the respective free energy barriers to form $\mathrm{CH}^{*} \mathrm{O}-\mathrm{H}^{*} \neq$ from $\mathrm{CO}^{*}$ and $\mathrm{H}_{2}\left(\Delta \mathrm{G}_{\gamma}{ }^{\dagger}\right)$ at these various locations, as given by Eqs. (25) and (26). In assessing the contributions to $\mathrm{CO}$ activation at these different locations, we first consider the $\left[\mathrm{C}_{n} \mathrm{H}_{2 n} *\right] /\left[\mathrm{C}_{n} \mathrm{H}_{2 n-1} *\right]$ and $\left[\mathrm{C}_{n} \mathrm{H}_{2 n+1} *\right] /\left[\mathrm{C}_{n} \mathrm{H}_{2 n-1} *\right]$ coverage ratios for these $\mathrm{C}_{1}$ species. $\mathrm{CH}^{*}$ binds at three-fold sites (Fig. 3C) and can react with $\mathrm{H}^{\prime}$ (from quasi-equilibrated $\mathrm{H}_{2}$ dissociation, Step 2 in Scheme 1) to form $\mathrm{CH}_{2}{ }^{*}$ :

$$
\mathrm{CH}^{*}+\mathrm{H}^{\prime} \rightarrow \mathrm{CH}_{2} *
$$

for which, the DFT-derived $\Delta H_{\mathrm{rxn}}$ value is $51 \mathrm{~kJ} \mathrm{~mol}^{-1}$ and the $\Delta G_{\mathrm{rxn}}$ value is $81 \mathrm{~kJ} \mathrm{~mol}^{-1}(500 \mathrm{~K}, 1 \mathrm{bar}$ $\mathrm{H}_{2}$ ). The assumption of quasi-equilibrium for Eq. 27 then leads to a maximum $\left[\mathrm{CH}_{2} *\right] /\left[\mathrm{CH}^{*}\right]$ ratio that depends on $\Delta G_{\mathrm{rxn}, 27}$ and on the $\mathrm{H}_{2}$ pressure $\left[\left(\mathrm{H}_{2}\right)\right.$ in bar]:

$$
\frac{\left[C H_{2}^{*}\right]}{\left[C H^{*}\right]}=e^{\left(\frac{-\Delta G_{r x n, 27}}{R T}\right)}\left(H_{2}\right)^{0.5}
$$

This ratio is $\sim 10^{-8}$ at 10 bar $\mathrm{H}_{2}$ and $500 \mathrm{~K}$ (Fig. 9). A similar analysis for the formation of $\mathrm{CH}_{3} *$ via $\mathrm{CH}_{2}$ * reactions with $\mathrm{H}^{\prime}$ : 


$$
\mathrm{CH}_{2}{ }^{*}+\mathrm{H}^{\prime} \rightarrow \mathrm{CH}_{3}{ }^{*}
$$

gives a maximum $\left[\mathrm{CH}_{3} *\right] /\left[\mathrm{CH}^{*}\right]$ ratio when equilibrated:

$$
\frac{\left[\mathrm{CH}_{3}^{*}\right]}{\left[C H^{*}\right]}=e^{\left(\frac{-\Delta G_{r \times n, 29}-\Delta G_{r \times n, 27}}{R T}\right)}\left(H_{2}\right)
$$

This value is $\sim 10^{-10}$ at 10 bar $\mathrm{H}_{2}$ and $500 \mathrm{~K}$ (Fig. 9). These very low concentrations of $\mathrm{CH}_{2} *$ and $\mathrm{CH}_{3}$ * relative to $\mathrm{CH}^{*}$ reflect the large $\Delta G_{\text {rxn }}$ of Eqs. 27 and $29\left(81\right.$ and $18 \mathrm{~kJ} \mathrm{~mol}^{-1}$ at $500 \mathrm{~K}, 1$ bar $\mathrm{H}_{2}$ ).

Figure 9. Ratios of $\mathrm{CH}_{2} *$ and $\mathrm{CH}_{3} *$ to $\mathrm{CH}^{*}$ at $500 \mathrm{~K}$ as a function of $\mathrm{H}_{2}$ pressure (bar). $\mathrm{H}_{2}$ pressures typical of FTS are shown in a shaded region.

The small concentrations of $\mathrm{CH}_{2} *$ and $\mathrm{CH}_{3} *$ relative to $\mathrm{CH}^{*}$ reflect their large $\Delta H_{\mathrm{rxn}}$ (51, and 46 $\mathrm{kJ} \mathrm{mol}^{-1}$, respectively) and $\Delta G_{\mathrm{rxn}}\left(81\right.$, and $102 \mathrm{~kJ} \mathrm{~mol}^{-1}$, respectively) $(500 \mathrm{~K})$ for their formation from $\mathrm{CH}^{*}$ and the stoichiometric amount of $\mathrm{H}_{2}$ (Fig. 10). The $\Delta G_{\text {Ixn }}$ values for the corresponding formation of $\mathrm{C}_{2}-\mathrm{C}_{4}$ alkylidenes from alkylidynes (and $1 / 2 \mathrm{H}_{2}(\mathrm{~g})$ ) are 99,102 , and $103 \mathrm{~kJ} \mathrm{~mol}^{-1}$, respectively, and thus even larger than for similar reactions of $\mathrm{C}_{1}$ * species (by $\sim 20 \mathrm{~kJ} \mathrm{~mol}^{-1}$; Fig. 10); the $\Delta G_{\mathrm{rxn}}$ values for the formation of $\mathrm{C}_{2}-\mathrm{C}_{4}$ alkyls from alkylidynes are 104, 97, and $107 \mathrm{~kJ} \mathrm{~mol}^{-1}$, respectively, and thus similar to that for the respective $\mathrm{C}_{1} *$ species $\left(102 \mathrm{~kJ} \mathrm{~mol}^{-1}, 500 \mathrm{~K}\right.$; Fig. 10). These $\Delta G_{\mathrm{rxn}}$ values indicate that alkylidynes are also the predominant $\mathrm{C}_{2}-\mathrm{C}_{4}$ species present as growing chains on $\mathrm{Ru}$ surfaces. At all conditions relevant to FTS practice, they represent the most abundant form of adsorbed chains, with alkyls and alkylidenes present as minority species (Eqs. 25 and 26; Fig. 9). These relative abundancies cast doubt upon $\mathrm{C}-\mathrm{C}$ bond formation through alkylidene insertions into alkyl chains suggested in literature [19,20,50,51], in favor of growth via alkylidyne species, as suggested elsewhere [22-25].

In light of these relative coverages, the free energy barriers to form $\mathrm{CH}^{*} \mathrm{O}-\mathrm{H}^{*} \neq\left(\Delta G_{\gamma}{ }^{\dagger}\right)$ near alkylidene and alkyl chains would have to be $\sim 100 \mathrm{~kJ} \mathrm{~mol}^{-1}$ lower than for forming $\mathrm{CH}^{*} \mathrm{O}-\mathrm{H}^{*} \ngtr$ near alkylidyne species for the CO* activation near alkylidene or alkyl chains to contribute to chain growth. First, we note that the $\Delta G_{\gamma}{ }^{\dagger}$ for $\mathrm{CO}^{*}$ activation near vacancies $\left(207 \mathrm{~kJ} \mathrm{~mol}^{-1}\right)$ was similar to that near $\mathrm{C}_{1^{-}}$ $\mathrm{C}_{4}$ alkylidyne chains (average of $213 \mathrm{~kJ} \mathrm{~mol}^{-1}$ ), indicating that the effects of co-adsorbates on $\Delta G_{\gamma}{ }^{\ddagger}$ are generally weakly repulsive. Furthermore, the binding modes of alkylidene and alkyl species (shown in Fig. 11B-C for $\mathrm{C}_{1}$ species) would lead to greater interference between those chains and $\mathrm{CH}^{*} \mathrm{O}-\mathrm{H}^{*} \neq$ 
(shown by a yellow-shaded overlay in Figs. 11E-F), in contrast to $\mathrm{CH}^{*} \mathrm{O}-\mathrm{H}^{*} \neq$ formation near $\mathrm{CH}^{*}$ (Fig. 11D). Alkylidyne chains are the most abundant form of growing chains on the catalyst surface (Fig. 9) and they effectively disrupt $\mathrm{CO}^{*}$-adlayers to facilitate further activations of $\mathrm{CO}^{*}$ species and thus rapidly increase the rate of chain growth over that of chain initiation.

Figure 10. Free energies $\left(\mathrm{kJ} \mathrm{mol}^{-1}, 500 \mathrm{~K}, 1\right.$ bar $\left.\mathrm{H}_{2}\right)$ to form alkylidene $\left(\mathrm{RCH}^{*}, \mathrm{R}=\mathrm{H}, \mathrm{CH}_{3}, \mathrm{C}_{2} \mathrm{H}_{5}\right.$, $\left.\mathrm{C}_{3} \mathrm{H}_{7}\right)$ and alkyl $\left(\mathrm{RCH}_{2}{ }^{*}\right)$ species from $\mathrm{C} 1-\mathrm{C} 4$ alkylidynes $\left(\mathrm{RC}^{*}\right)\left(\mathrm{C}_{1}: \boldsymbol{\bullet}, \mathrm{C}_{2}: \mathbf{\square}, \mathrm{C}_{3}: \mathbf{\Delta}, \mathrm{C}_{4}: \boldsymbol{\nabla}\right)$ and a stoichiometric amount of $\mathrm{H}_{2}$. Also shown is the free energy to form $\mathrm{C}^{*}$ (and $1 / 2 \mathrm{H}_{2}(\mathrm{~g})$ ) from $\mathrm{CH}^{*}$.

Figure 11. $A-D)$ DFT-calculated structures of $\mathrm{CH}^{*}, \mathrm{CH}_{2} *, \mathrm{CH}_{3} *$, and the ${ }^{*} \mathrm{CHO}-\mathrm{H}^{*} \neq$ transition state vicinal to a $\mathrm{CH}^{*} . \boldsymbol{E}-\boldsymbol{F}$ ) Overlays of DFT-calculated structures for $\mathrm{CH}_{2} *$ and $\mathrm{CH}_{3} *$ with the $* \mathrm{CHO}-\mathrm{H}^{*} \neq$ transition state from $(\boldsymbol{D})$.

\section{Conclusions}

Chains grow much more rapidly than they initiate during FTS on Ru and Co surfaces, which appears inconsistent with chain growth via $\mathrm{CH}_{x}{ }^{*}$-insertion (carbene-like) mechanisms as $\mathrm{CH}_{x}{ }^{*}$ species have to be created via $\mathrm{CO}^{*}$ activation processes identical to those which initiate chains. Here, this inconsistency is resolved through the use of DFT calculations at the high CO* coverages (1.04 ML) relevant to FTS by demonstrating that alkylidyne hydrocarbon chains $\left(\mathrm{C}_{n} \mathrm{H}_{2 n-1}{ }^{*}, n=1-4\right)$ disrupt the $\mathrm{CO}^{*}$ adlayer and permit $\mathrm{H}$-assisted $\mathrm{CO}^{*}$ activation without $\mathrm{CO}^{*}$ desorption, leading to activation enthalpies and free energies $\sim 100$ and $\sim 15 \mathrm{~kJ} \mathrm{~mol}^{-1}$ lower for $\mathrm{CO}^{*}$ activation near chains than within unperturbed monolayers. Alkylidyne species are much more abundant $\left(\right.$ by $\sim 10^{8}$ ) than alkylidene or alkyl species which do not permit $\mathrm{CO}^{*}$ activation at vicinal sites. Once formed, $\mathrm{CH}^{*}$ species can easily form $\mathrm{C}-\mathrm{C}$ bonds with hydrocarbon chains (activation free energies $<100 \mathrm{~kJ} \mathrm{~mol}^{-1}$ ), ultimately leading to observed alkene and alkane products. Co follows the same rate law and displays similar product distributions and measured activation barriers as Ru, indicating that the mechanism for FTS is likely similar on both metals. Thus, we consider the ability of $\mathrm{CO}^{*}$ to activate more rapidly near chains to by applicable to both metals.

\section{Acknowledgements}


The authors acknowledge the financial support and computational resources provided by BP through the X-Conversion Consortium (BP-XC ${ }^{2}$ ). We thank Drs. Craig Plaisance, Corneliu Buda, Jay Labinger, John Shabaker, and George Huff for helpful technical discussions. Computational resources were also provided by the Molecular Science Computing Facility (MSCF) in the William R. Wiley Environmental Molecular Sciences Laboratory, a national scientific user facility sponsored by the U.S. Department of Energy, Office of Biological and Environmental Research at the Pacific Northwest National Laboratory.

\section{References}

[1] F. Fischer, H. Tropsch, Brennstoff-Chemie, Bd 7 (1926) 97-116.

[2] E. Iglesia, Appl. Catal. A Gen. 161 (1997) 59-78.

[3] M. Vannice, Catal. Rev. Eng. 14 (1976) 153-191.

[4] C.A. Mims, L.E. McCandlish, J. Phys. Chem. 91 (1987) 929-937.

[5] R.S. Dixit, L.L. Tavlarides, Ind. Eng. Chem. Process Des. Dev. 22 (1983) 1-9.

[6] M. Ojeda, R. Nabar, A.U. Nilekar, A. Ishikawa, M. Mavrikakis, E. Iglesia, J. Catal. 272 (2010) 287-297.

[7] I.C. Yates, C.N. Satterfield, Energy \& Fuels 5 (1991) 168-173.

[8] B.T. Loveless, C. Buda, M. Neurock, E. Iglesia, J. Am. Chem. Soc. 135 (2013) 6107-21.

[9] P. Winslow, A.T. Bell, J. Catal. 86 (1984) 158-172.

[10] D.D. Hibbitts, B.T. Loveless, M. Neurock, E. Iglesia, Angew. Chem. Int. Ed. Engl. 52 (2013) 12273-8.

[11] M. Ojeda, A. Li, R. Nabar, A.U. Nilekar, M. Mavrikakis, E. Iglesia, J. Phys. Chem. C 114 (2010) 19761-19770. 
[12] O.R. Inderwildi, S.J. Jenkins, D.A. King, J. Phys. Chem. C 112 (2008) 1305-1307.

[13] H. Pichler, H. Schulz, Chemie Ing. Tech. 42 (1970) 1162.

[14] M. Zhuo, K.F. Tan, A. Borgna, M. Saeys, J. Phys. Chem. C 113 (2009) 8357-8365.

[15] Y.H. Zhao, K. Sun, X. Ma, J. Liu, D. Sun, H.Y. Su, W.X. Li, Angew. Chemie - Int. Ed. 50 (2011) 5335-5338.

[16] M. Zhuo, A. Borgna, M. Saeys, J. Catal. 297 (2013) 217-226.

[17] B. Todic, W. Ma, G. Jacobs, B.H. Davis, D.B. Bukur, Catal. Today 228 (2014) 32-39.

[18] R. a. VanSanten, A.J. Markvoort, ChemCatChem 5 (2013) 3384-3397.

[19] R. Brady, R. Pettit, J. Am. Chem. Soc. 102 (1980) 6181-6182.

[20] R.C. Brady, R. Pettit, J. Am. Chem. Soc. 103 (1981) 1287-1289.

[21] C.A. Mims, L.E. McCandlish, M.T. Melchior, Catal. Letters 1 (1988) 121-125.

[22] I.M. Ciobîcă, G.J. Kramer, Q. Ge, M. Neurock, R. a. van Santen, J. Catal. 212 (2002) 136-144.

[23] Z.-P. Liu, P. Hu, J. Am. Chem. Soc. 124 (2002) 11568-9.

[24] M.L. Turner, N. Marsih, B.E. Mann, R. Quyoum, H.C. Long, P.M. Maitlis, J. Am. Chem. Soc. 124 (2002) 10456-72.

[25] J. Cheng, P. Hu, P. Ellis, S. French, G. Kelly, C.M. Lok, (2008) 6082-6086.

[26] P.M. Maitlis, V. Zanotti, Catal. Letters 122 (2008) 80-83.

[27] G. Kresse, J. Hafner, Phys. Rev. B 47 (1993) 558-561.

[28] G. Kresse, J. Hafner, Phys. Rev. B 49 (1994) 14251-14269. 
[29] G. Kresse, J. Furthmüller, Phys. Rev. B Condens. Matter Mater. Phys. 54 (1996) 11169-11186.

[30] G. Kresse, J. Furthmüller, Comput. Mater. Sci. 6 (1996) 15-50.

[31] P. Blöchl, Phys. Rev. B 50 (1994) 17953-17979.

[32] G. Kresse, D. Joubert, Phys. Rev. B Condens. Matter Mater. Phys. 59 (1999) 11-19.

[33] J. Perdew, K. Burke, M. Ernzerhof, Phys. Rev. Lett. 77 (1996) 3865-3868.

[34] Y. Zhang, W. Yang, Phys. Rev. Lett. 80 (1998) 890.

[35] B. Hammer, L. Hansen, J.K. Nørskov, Phys. Rev. B Condens. Matter Mater. Phys. 59 (1999) 7413-7421.

[36] J. Klimeš, D. Bowler, A. Michaelides, Phys. Rev. B 83 (2011) 1-13.

[37] K. Lee, D. Murray, L. Kong, B.I. Lundqvist, D.C. Langreth, É.D. Murray, L. Kong, B.I. Lundqvist, D.C. Langreth, Phys. Rev. B 82 (2010) 081101(R).

[38] S. Grimme, J. Antony, S. Ehrlich, H. Krieg, J. Chem. Phys. 132 (2010) 154104.

[39] S. Grimme, S. Ehrlich, L. Goerigk, J. Comput. Chem. 32 (2011) 1456-1465.

[40] H. Monkhorst, J. Pack, Phys. Rev. B 13 (1976) 5188-5192.

[41] J. Liu, D. Hibbitts, E. Iglesia, To Be Submitt. (n.d.).

[42] D.E. Starr, H. Bluhm, Surf. Sci. 608 (2013) 241-248.

[43] H. Jonsson, G. Mills, H. Jónsson, K.W. Jacobsen, Class. Quantum Dyn. Condens. Phase Simulations - Proc. Int. Sch. Phys. (1998) 385-404.

[44] G. Henkelman, H. Jónsson, H. Jo, I. Introduction, H. Jónsson, J. Chem. Phys. 113 (2000) 9978. 
[45] G. Henkelman, H. Jónsson, J. Chem. Phys. 111 (1999) 7010.

[46] J.P. den Breejen, P.B. Radstake, G.L. Bezemer, J.H. Bitter, V. Frøseth, A. Holmen, K.P. de Jong, J. Am. Chem. Soc. 131 (2009) 7197-203.

[47] J.M.G. Carballo, J. Yang, A. Holmen, S. García-Rodríguez, S. Rojas, M. Ojeda, J.L.G. Fierro, J. Catal. 284 (2011) 102-108.

[48] M. Gajdo, A. Eichler, J. Hafner, J. Phys. Condens. Matter 16 (2004) 1141-1164.

[49] F. Abild-Pedersen, M.P. Andersson, Surf. Sci. 601 (2007) 1747-1753.

[50] E. van Steen, H. Schulz, Appl. Catal. A Gen. 186 (1999) 309-320.

[51] H. Schulz, E. vein Steen, M. Claeys, Stud. Surf. Sci. Catal. 81 (1994) 455-460. 


\section{$\mathrm{CO}+* \rightleftharpoons \mathrm{CO}^{*}$}

(1)

$\mathrm{H}_{2}+* \rightleftharpoons 2 \mathrm{H}^{\prime}+*$

(2)

$\mathrm{CO}^{*}+*+\mathrm{H}^{\prime} \rightleftharpoons \mathrm{HC}^{*} \mathrm{O}^{*}$

(3)

$\mathrm{HC}^{*} \mathrm{O}^{*}+\mathrm{H}^{\prime} \longrightarrow \mathrm{CH}^{*} \mathrm{OH}^{*}$

(4)

$\mathrm{CH}^{*} \mathrm{OH}^{*} \longrightarrow \mathrm{CH}^{*}+\mathrm{OH}^{*}$

(5)

$\mathrm{CH}^{*}+\mathrm{OH}^{*}+\mathrm{H}^{\prime} \longrightarrow \mathrm{CH}^{*}+\mathrm{H}_{2} \mathrm{O}+*$ 


\section{Figure 1}

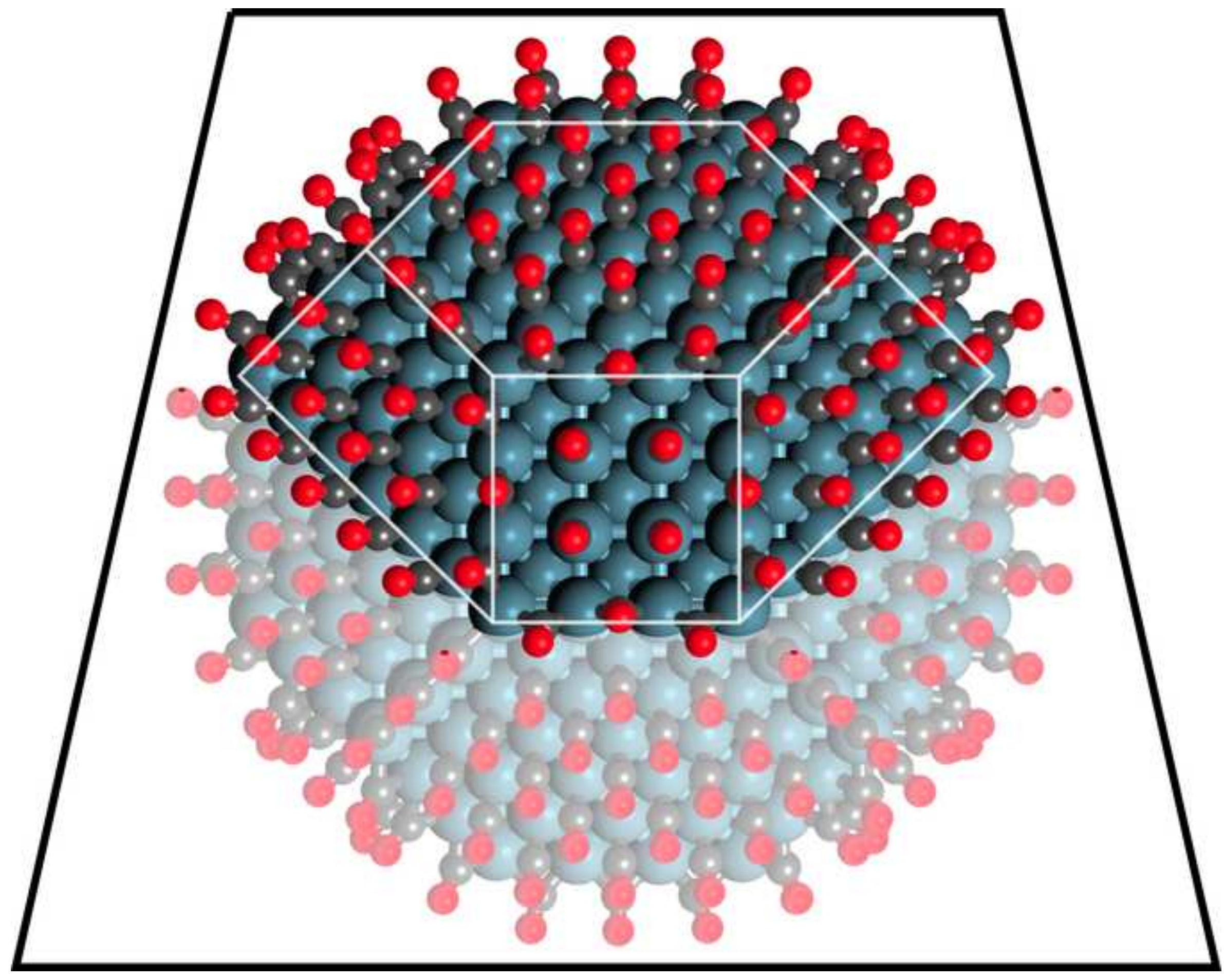


A)

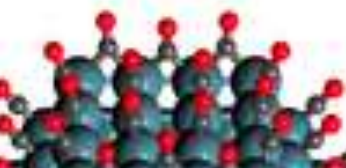

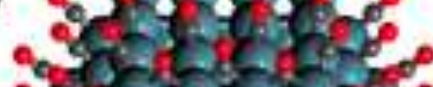

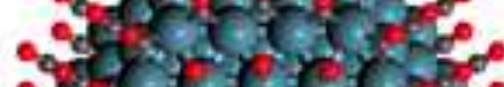

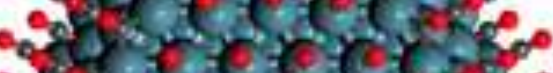

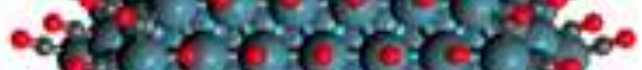

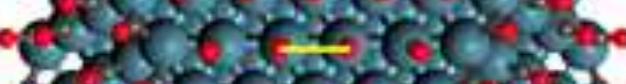

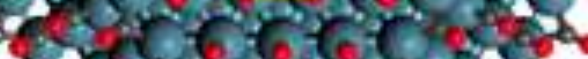

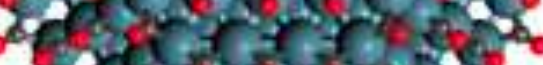

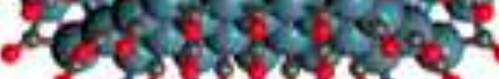

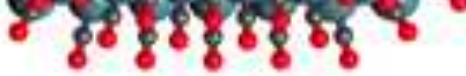
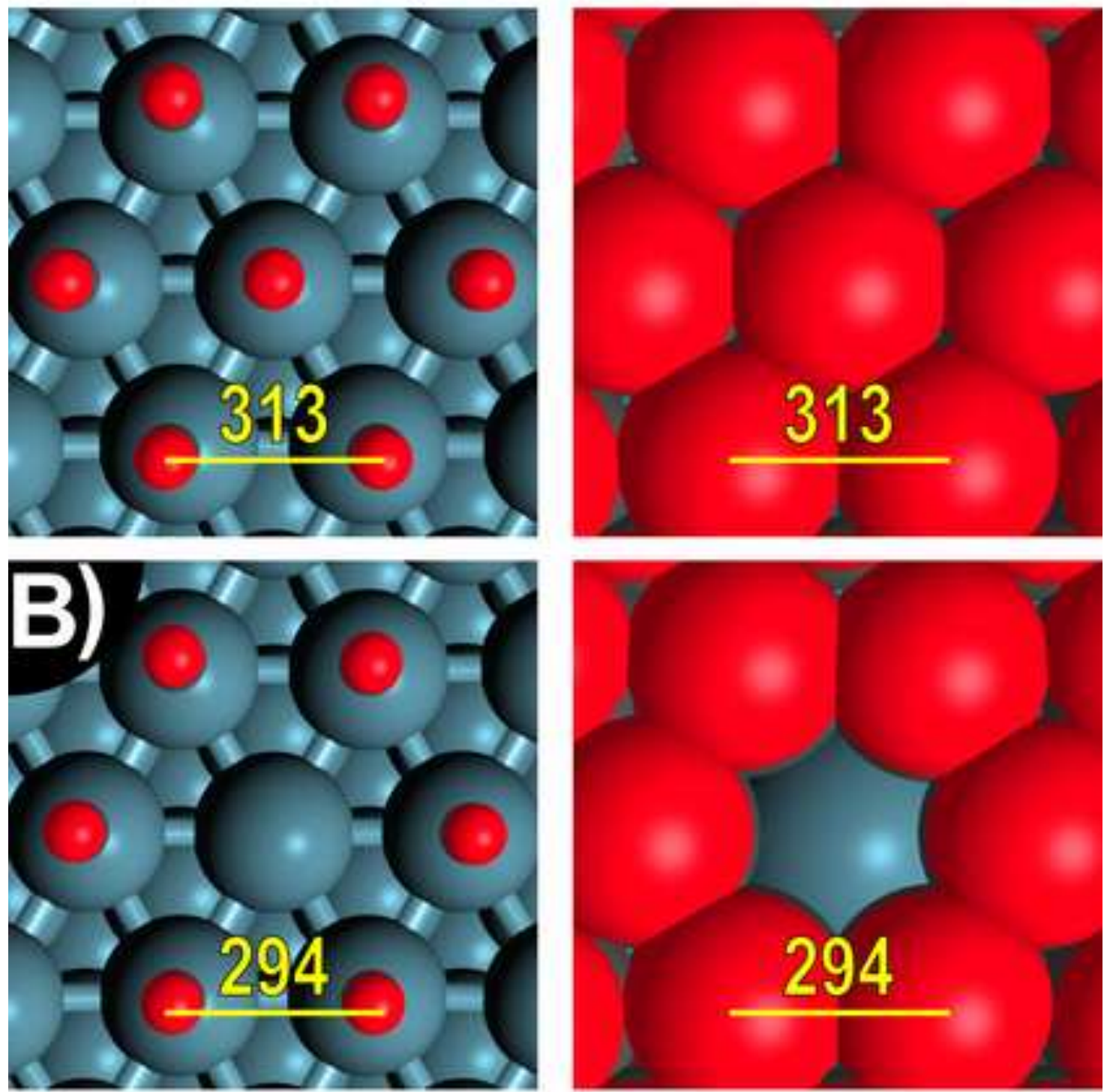

$\Delta H_{\text {ads,co }}$
$\Delta S_{\text {ads,co }}$
$\Delta G_{\text {ads,co }}$

$\frac{\text { RPBE }}{-46} \quad \frac{\mathrm{D} 3(\mathrm{NMI})}{-104}$ $-165$

$-165$

$+36$

$-22$ 
Figure 3

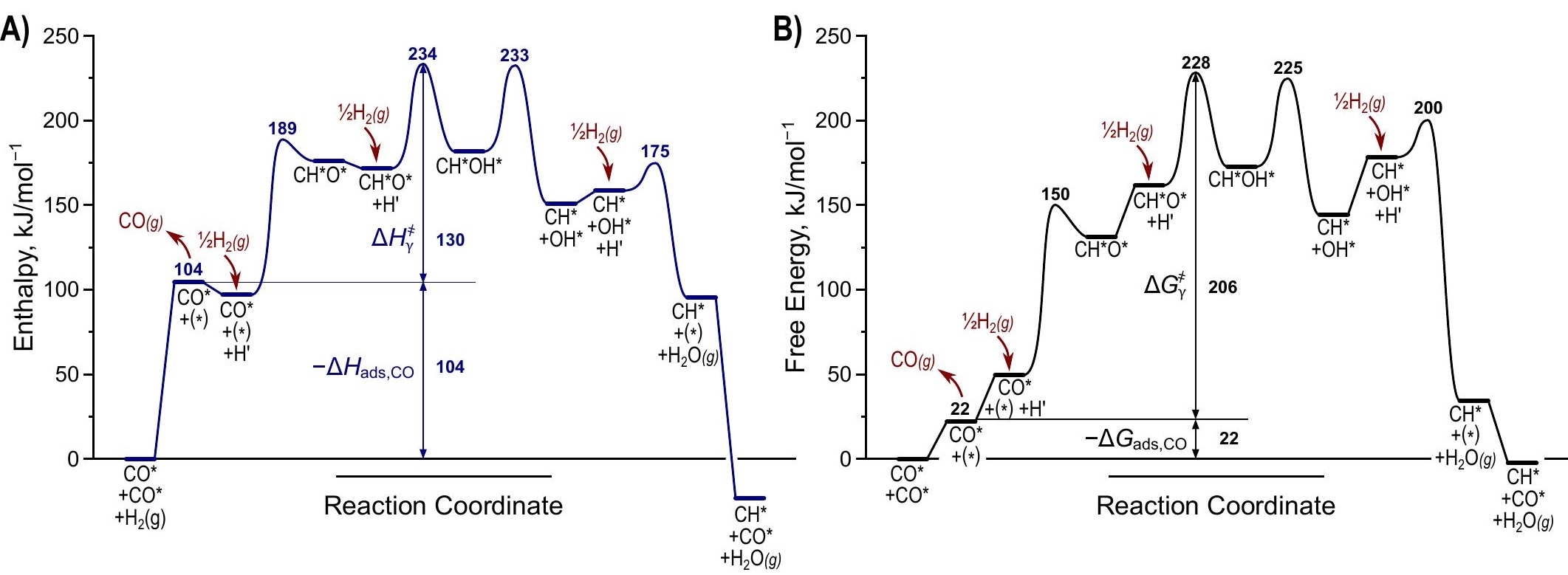




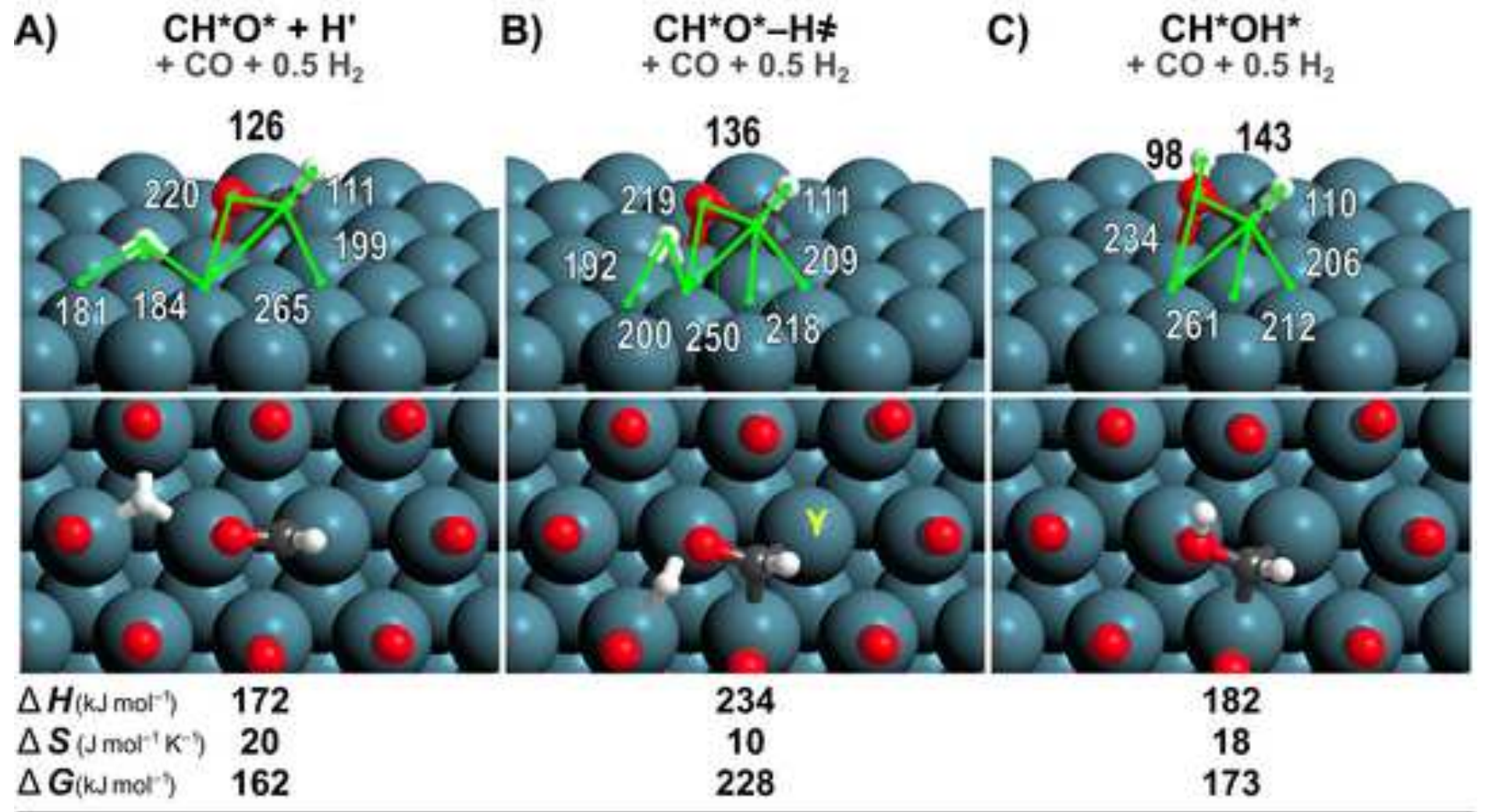

\begin{tabular}{|c|c|c|c|}
\hline D) & $\begin{array}{c}\mathrm{CH}^{*}+\mathrm{OH}^{*} \\
+\mathrm{CO}+0.5 \mathrm{H}_{2}\end{array}$ & E) & $\begin{aligned} \mathrm{CH}^{*} & +\mathrm{OH}^{*}-\mathrm{H} \neq \\
& +\mathrm{CO}\end{aligned}$ \\
\hline
\end{tabular}

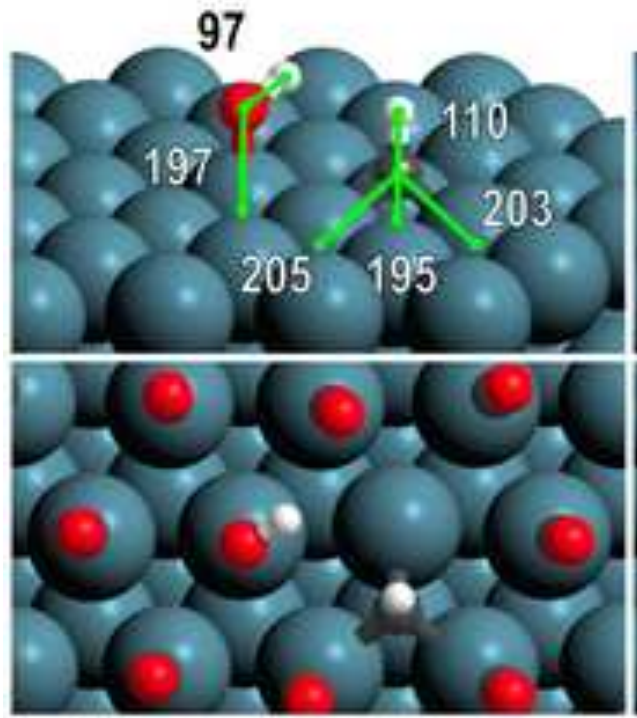

$\Delta H$ (kJ mol') $\quad 155$

$\Delta S\left(\mathrm{~J} \mathrm{~mol}^{-1} \mathrm{~K}^{-1}\right) \quad 15$

$\Delta G\left(k^{\prime} \mathrm{mol}^{-1}\right) \quad 137$

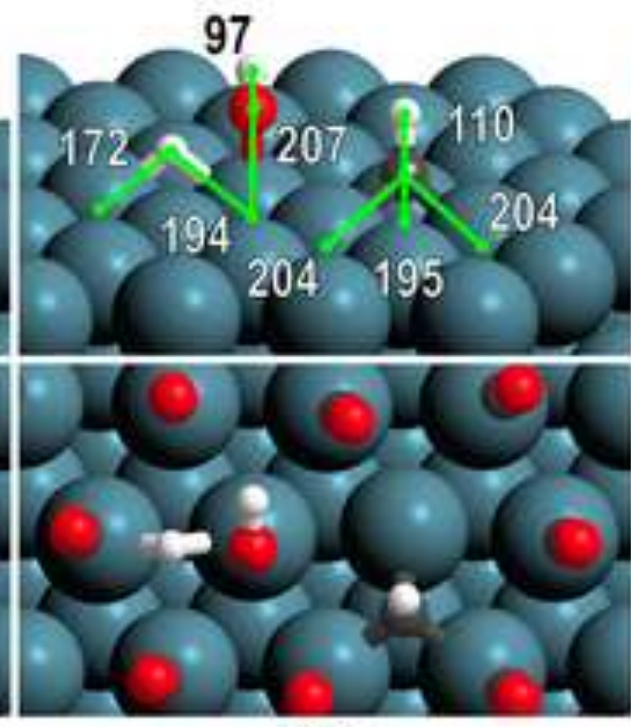

175

$-51$

200
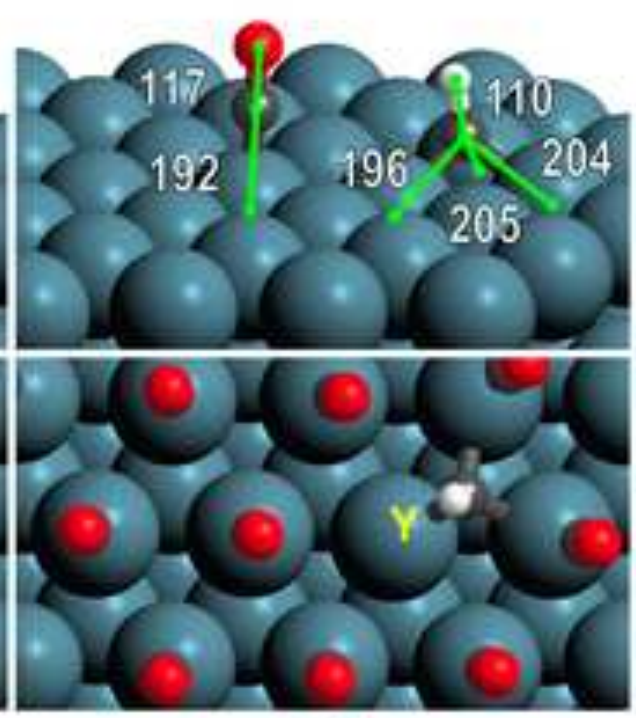

$-23$

$-41$

$-2$ 
A) $\begin{gathered}\mathrm{CH}^{*}+\mathrm{CH}^{\prime} \\ +\mathrm{H}_{2} \mathrm{O}\end{gathered}$

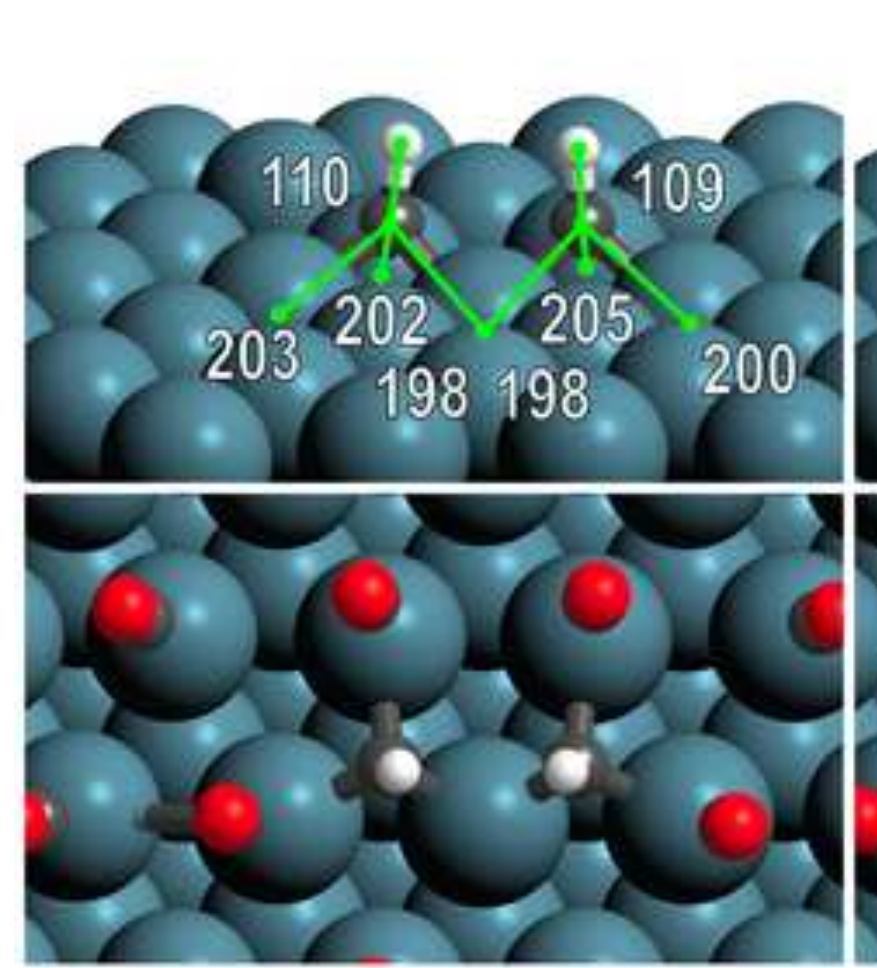

$\left.\Delta \boldsymbol{H}_{(\mathrm{kJ} \mathrm{mol}}{ }^{-1}\right) \quad \mathbf{0}$

$\Delta S\left(\mathrm{~J} \mathrm{~mol}^{-1} \mathrm{~K}^{-1}\right) \quad 0$

$\Delta G\left(\mathrm{~kJ} \mathrm{~mol}^{-}\right) \quad 0$
B) $\mathrm{CH}^{*}-\mathrm{CH}^{\prime} \neq$

$+\mathrm{H}_{2} \mathrm{O}$
C)

$\mathrm{CHCH}^{*}$

$+\mathrm{H}_{2} \mathrm{O}$

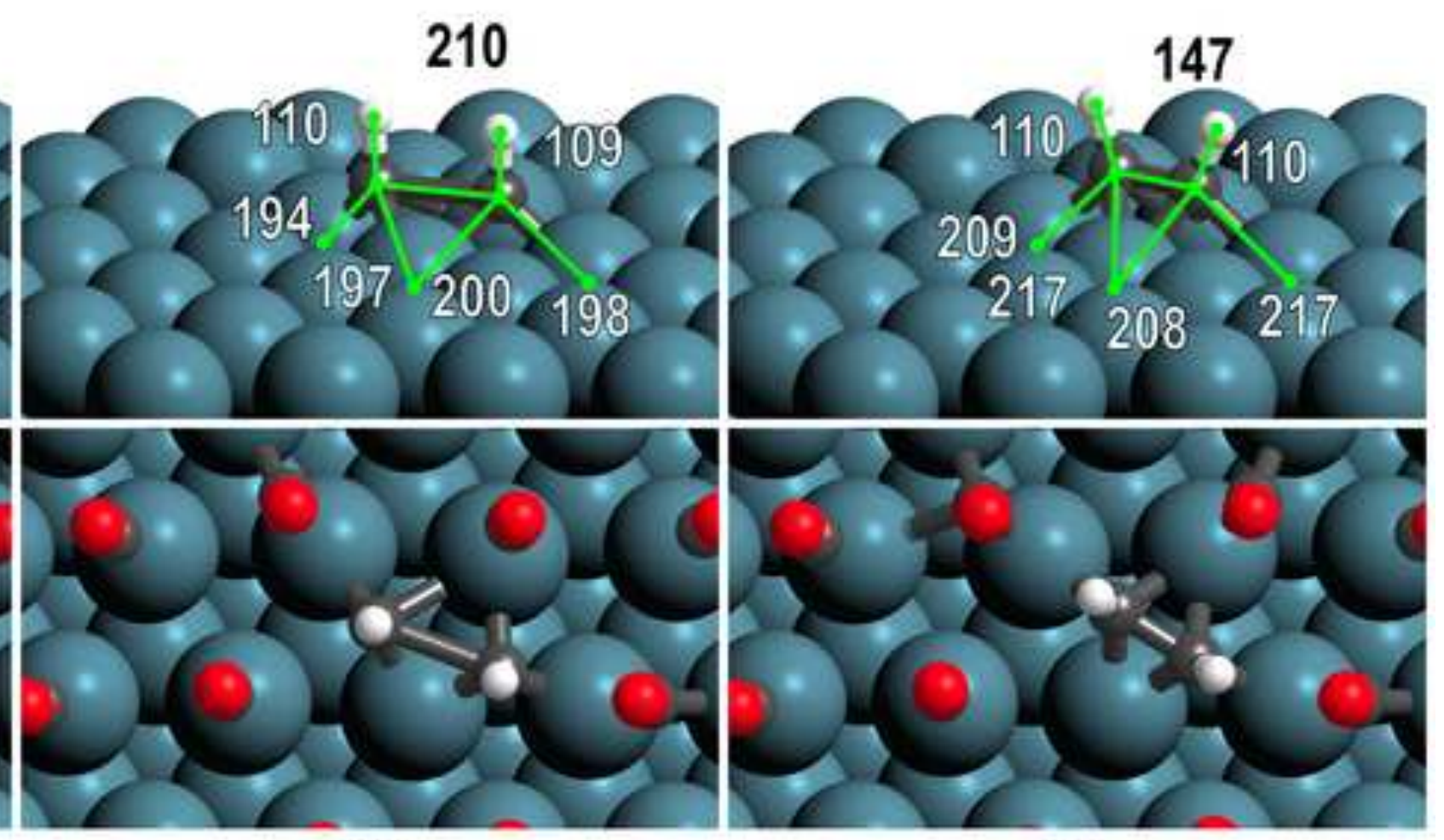

88

$-10$

94
50

3 49 


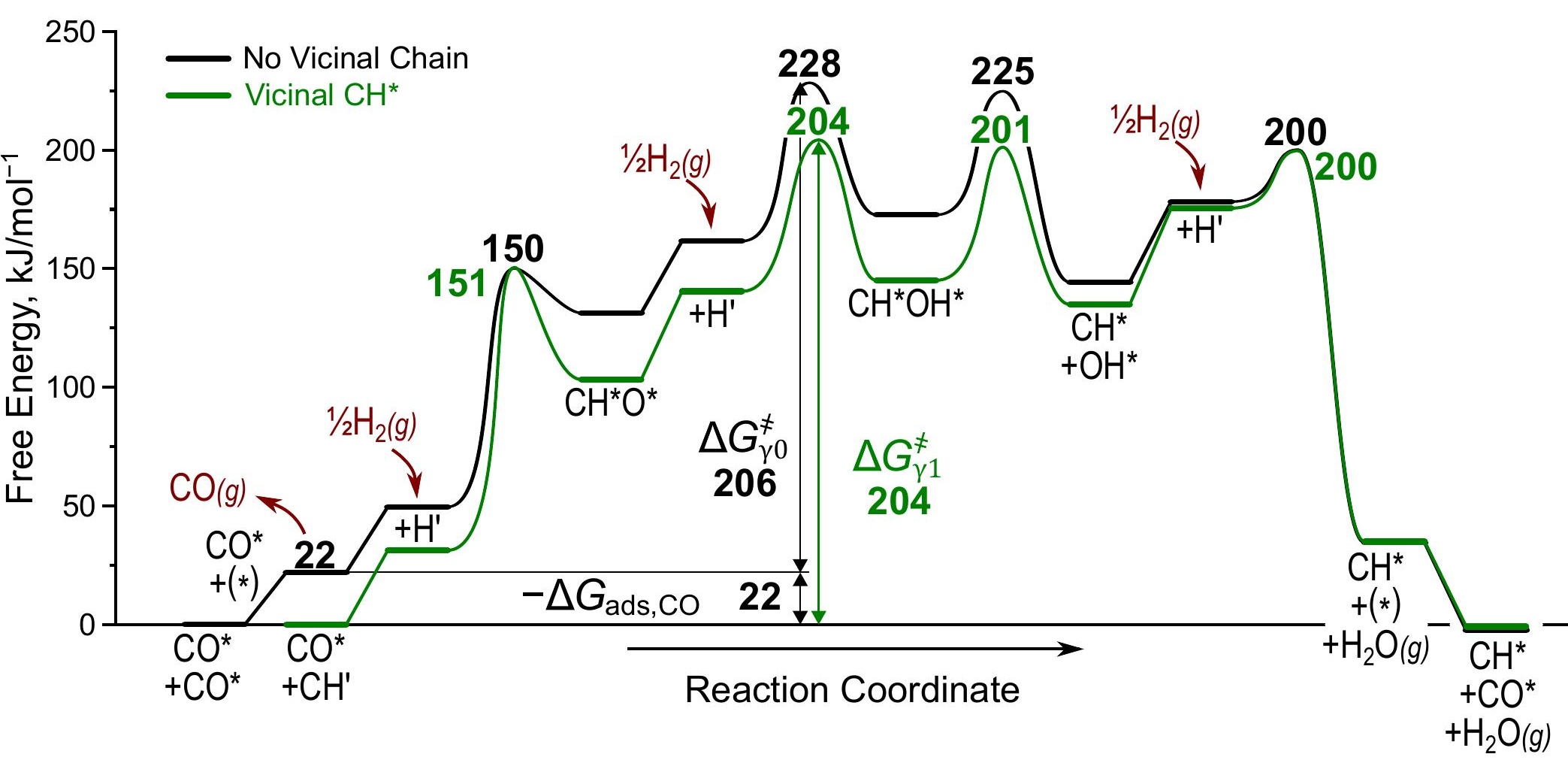




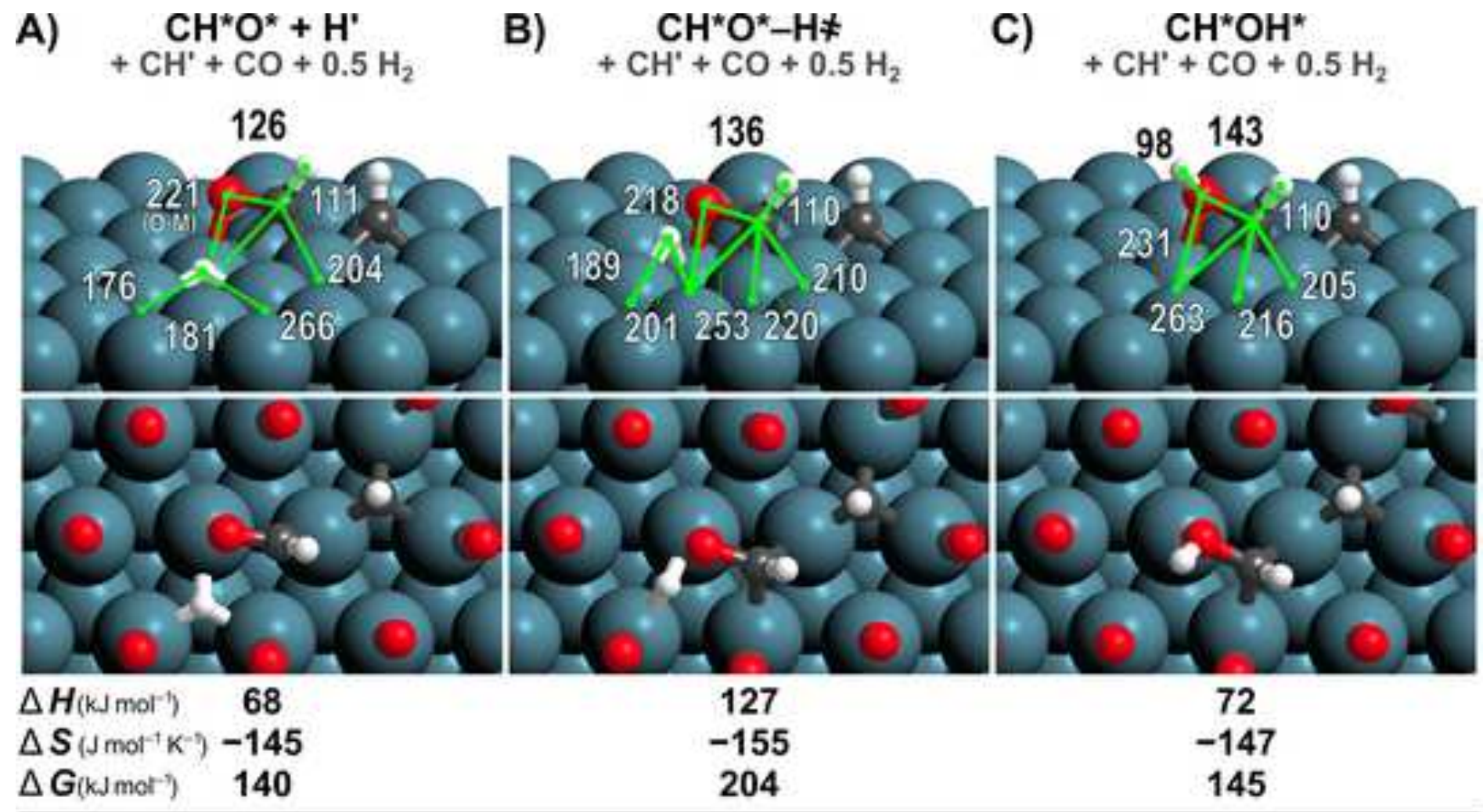

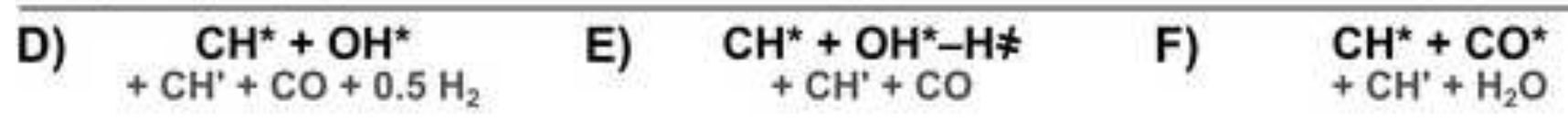
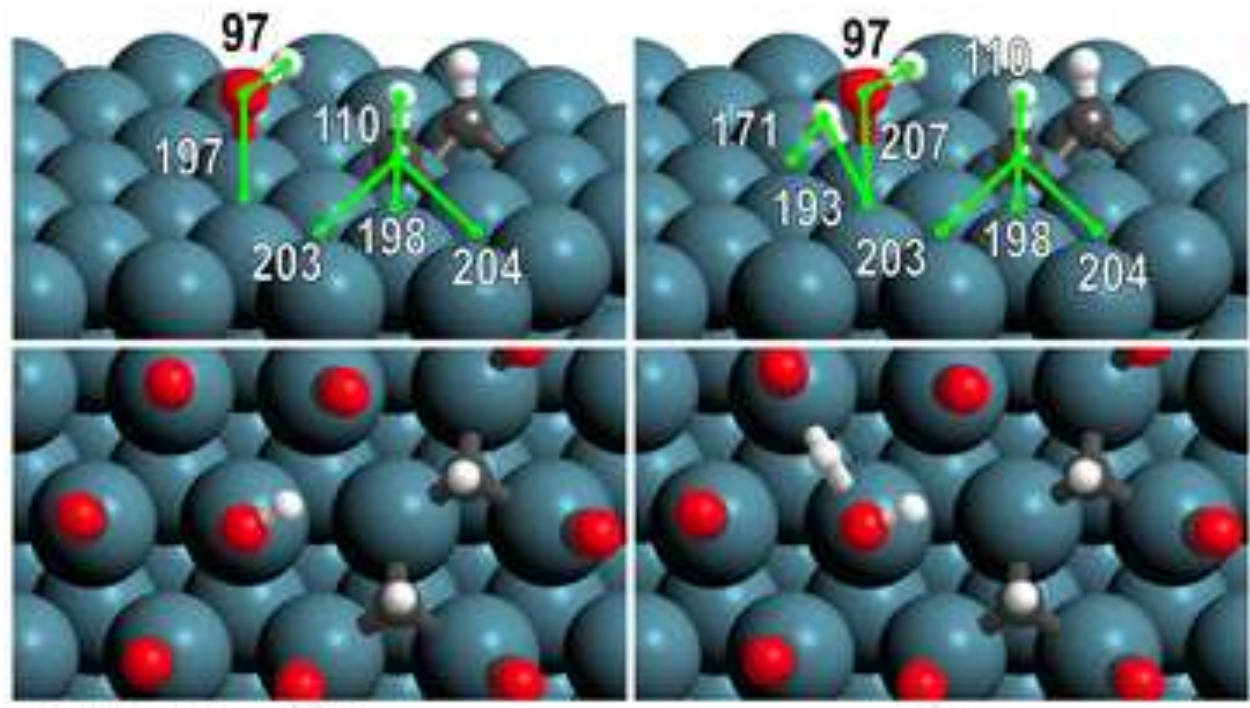

$\Delta \boldsymbol{H}_{\left(\mathrm{kJ} \mathrm{mol}^{-1}\right)} \mathbf{6 8}$

$\Delta S\left(J \mathrm{~mol}^{-1} \mathrm{~K}\right) \mathrm{S}-133$

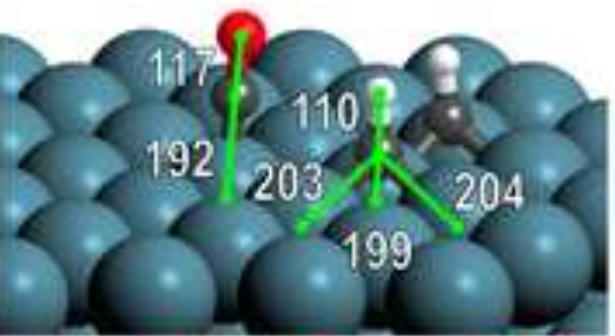

$\Delta G_{\left(k J \mathrm{~mol}^{-}\right)} \mathbf{1 3 5}$

$-214$

200
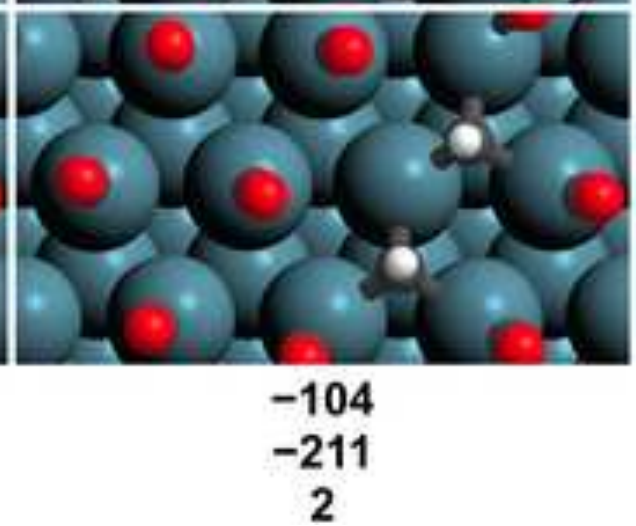


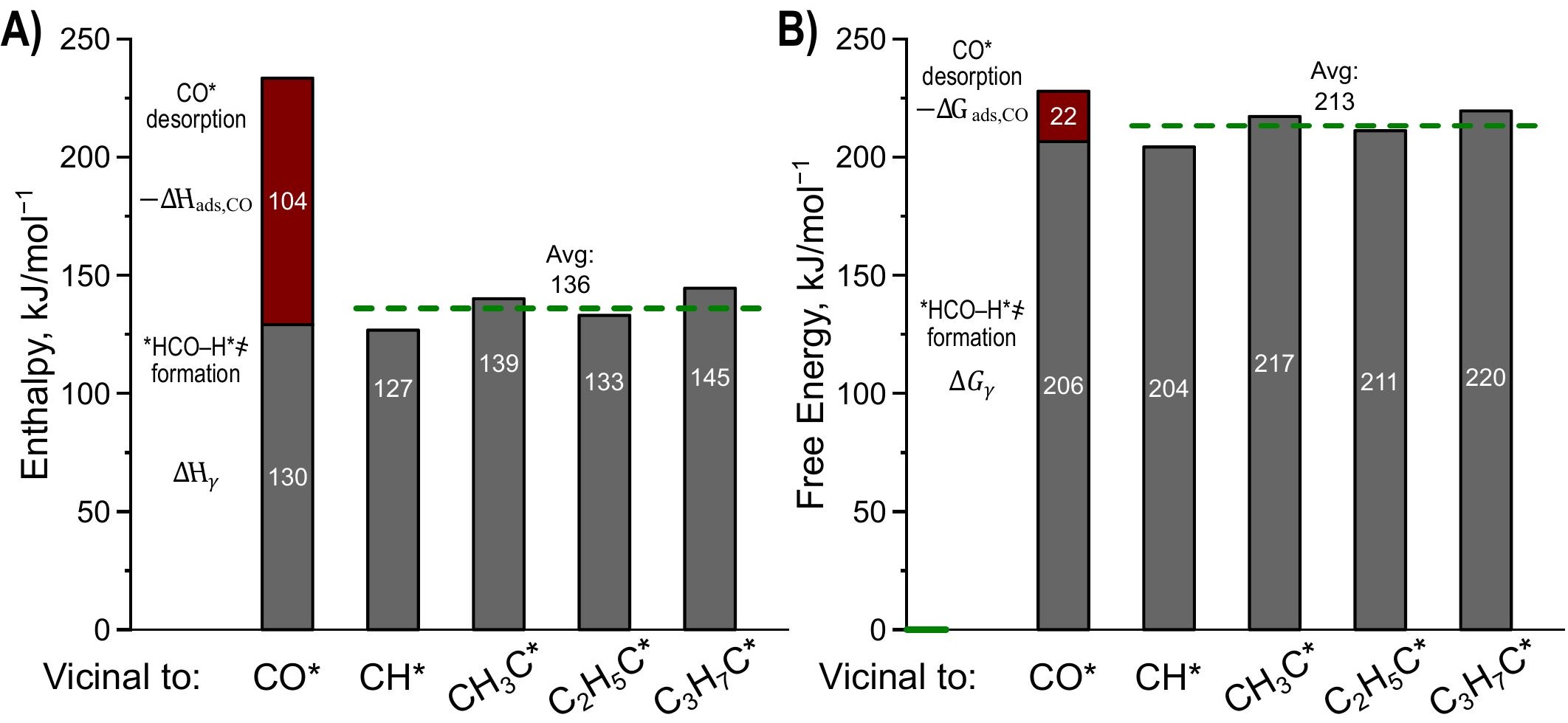


Figure 9

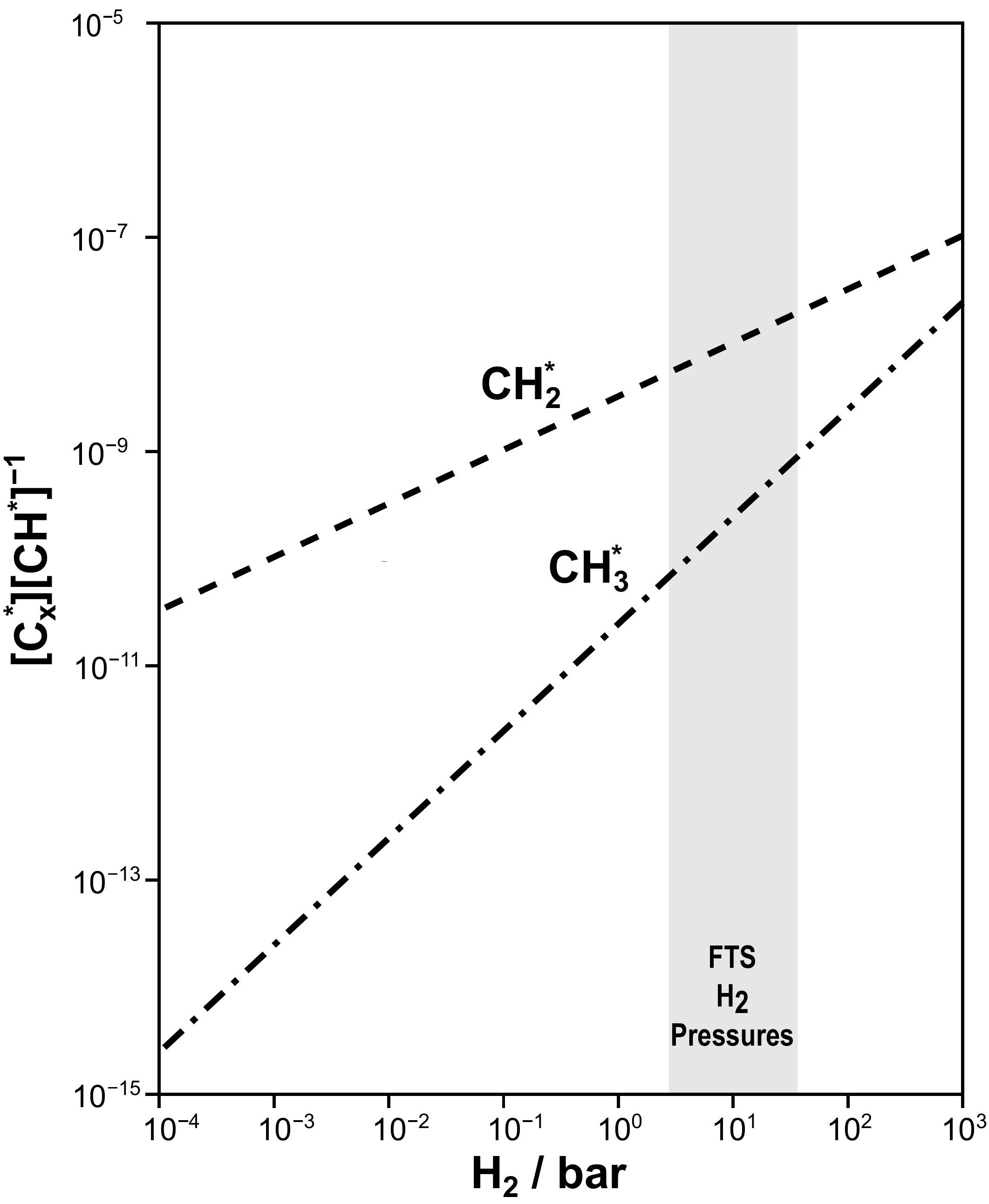




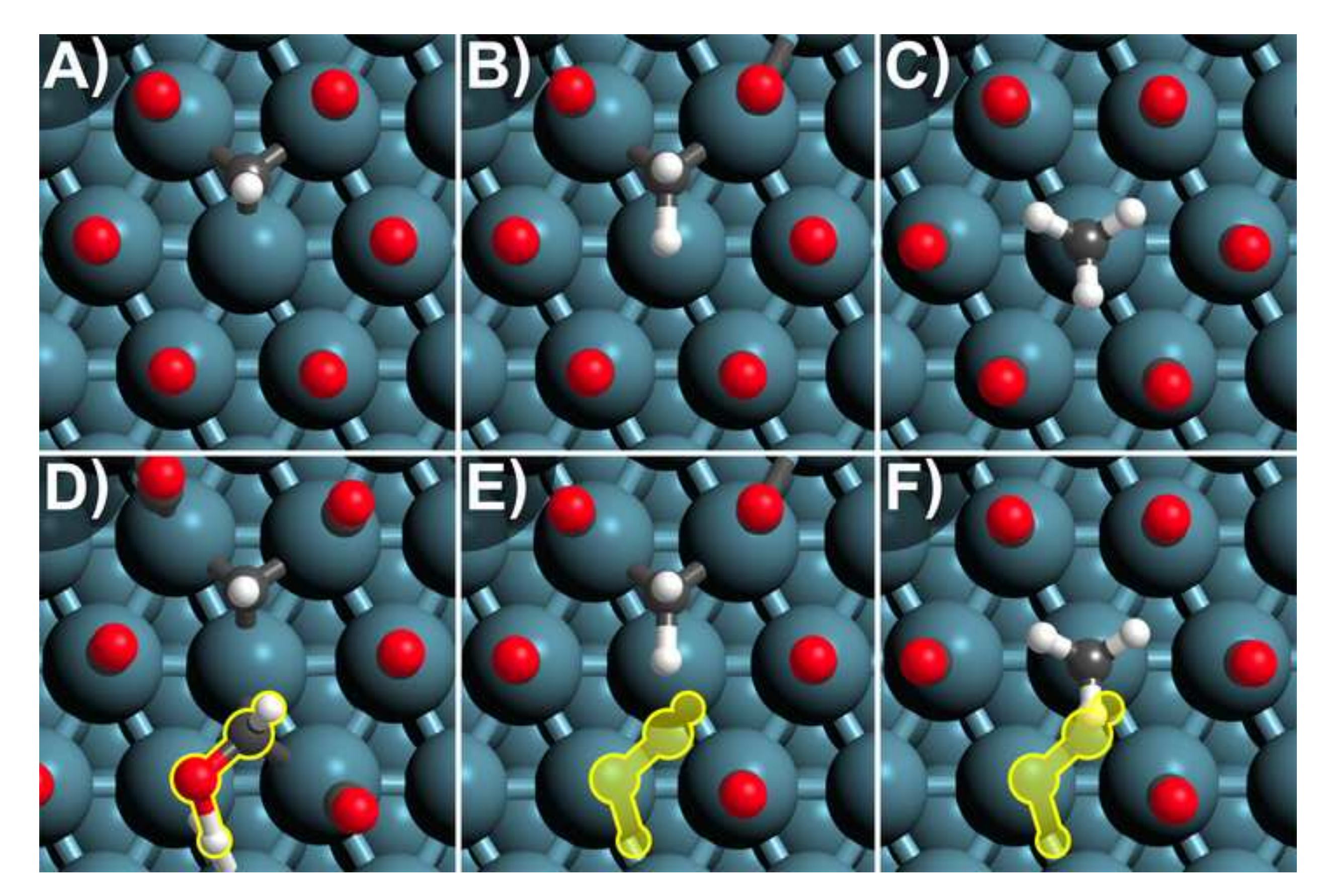

\footnotetext{
-
} 
Rates of FTS are linearly proportional to $\mathrm{H}_{2}$ pressure, this much is uncontroversial throughout literature. [Loveless, B; et al. J. Am. Chem. Soc. 2013, 135, 6107. Ojeda, M; et al. J. Catal. 2010, 272, 287. Iglesia, E. Appl. Catal., A 1997, 161, 59. Dixit, R.; Talvarides, L. Ind. Eng. Chem. Process Des. Dev. 1983, 22, 1. Yates, I.; Satterfield, C. Energy Fuels 1991, 5, 168. and others]. Unpublished work by our group demonstrates that at low-pressure conditions (CO pressures near less than $100 \mathrm{kPa}$ ) and higher temperatures $(573 \mathrm{~K})$, rates of $\mathrm{CO}$ consumption on $\mathrm{Ru}$ catalysts remain linearly proportional to $\mathrm{H}_{2}$ pressure (Fig. R1) with methane selectivities near $100 \%$.
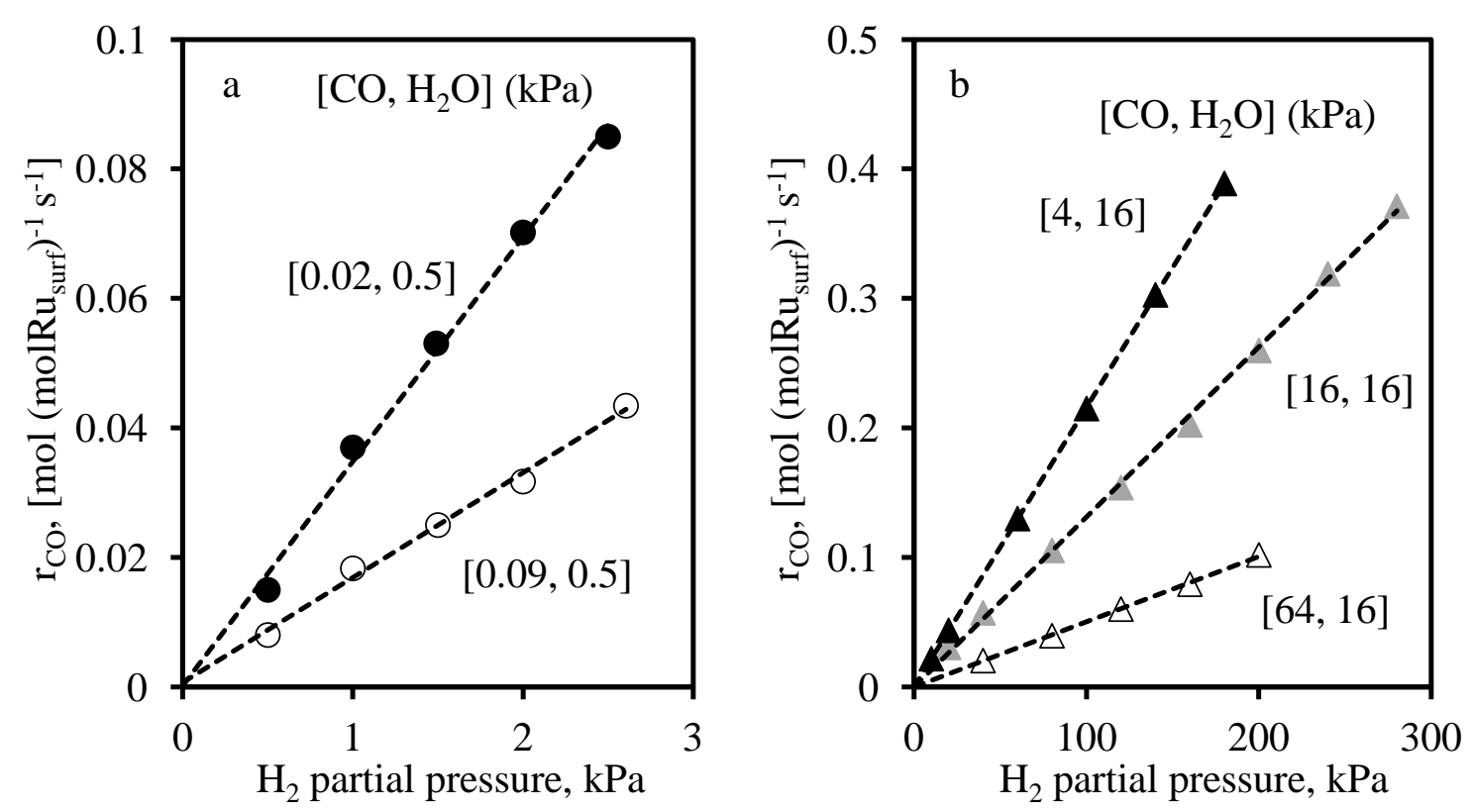

Figure R1. CO hydrogenation turnover rate as the function of $\mathrm{H}_{2}(\mathrm{a}, \mathrm{b})$ and $\mathrm{H}_{2} \mathrm{O}$ (c, d) partial pressures on $5 \%$ wt. $\mathrm{Ru} / \mathrm{SiO}_{2}\left(7.5 \mathrm{~nm}\right.$ clusters) at $573 \mathrm{~K}$ (a, c effect of $\mathrm{H}_{2}$ and $\mathrm{H}_{2} \mathrm{O}$ partial pressure at low $\mathrm{CO}$ partial pressures $(<0.1 \mathrm{kPa})$; b, d effect of $\mathrm{H}_{2}$ and $\mathrm{H}_{2} \mathrm{O}$ partial pressure at high CO partial pressures $(>0.4 \mathrm{kPa})$

This data indicates that the $\mathrm{H}_{2}$-dependence in the rate equation observed at FTS conditions:

$$
r=\frac{\alpha(\mathrm{CO})\left(\mathrm{H}_{2}\right)}{\left[1+K_{\mathrm{CO}}(\mathrm{CO})\right]^{2}}
$$

remains the same at the low pressures and higher temperatures associated with methanation reactions on $\mathrm{Ru}$. To eliminate account for the well-understood effects of $\mathrm{H} 2$ on rates of methanation (and FTS), we can plot the $r \cdot\left(\mathrm{H}_{2}\right)^{-1}$, noting that the resulting rearrangement of Eq. $\mathrm{R} 1$ leaves only the $\mathrm{CO}$ pressure term on the right-hand-side of the equation.

$$
\frac{r}{\left(\mathrm{H}_{2}\right)}=\frac{\alpha(\mathrm{CO})}{\left[1+K_{\mathrm{CO}}(\mathrm{CO})\right]^{2}}
$$


The form of Eq. R2 dictates that at $\mathrm{CO}^{*}$ coverages less than $0.5 \mathrm{ML}$, increasing $\mathrm{CO}$ pressure will increase $\mathrm{CO}$ consumption turnover rates. Similarly, at $\mathrm{CO}^{*}$ coverages greater than $0.5 \mathrm{ML}$, rates will decrease with increasing $\mathrm{CO}$ pressure and at $\mathrm{CO}^{*}$ coverages near $1 \mathrm{ML}$ they will be inversely proportional to $\mathrm{CO}$ pressure.

If the lumped rate constant in the numerator $(\alpha)$ and the equilibrium constant for $\mathrm{CO}$ adsorption $\left(\mathrm{K}_{\mathrm{CO}}\right)$ remain constant as $\mathrm{CO}$ pressure (and thus coverage) changes, then Eq. R2 should fit all data and we can calculate the coverage of $\mathrm{CO}^{*}$ from the effects of $\mathrm{CO}$ pressure on rate.

Figure $\mathrm{R} 2$ shows the effect of $\mathrm{CO}$ pressure on $\mathrm{CO}$ consumption turnover rates (divided by $\mathrm{H}_{2}$ pressure) over a wide range of $\mathrm{CO}$ pressures (over four orders of magnitude) and three different temperatures $(548,573$, and $598 \mathrm{~K})$. Also plotted is the fit of Equation R2 to low-pressure data (CO pressures less than $0.1 \mathrm{kPa}$ ). There is good agreement between the regressed form of Equation R2 and the measured kinetic data for all three temperatures in this low pressure regime, however, the fit becomes demonstrably worse at higher pressures as rates exceed their expected values based on the extrapolated data. The inhibitory effects of $\mathrm{CO}$ pressure on $\mathrm{CO}$ hydrogenation also get weaker with increasing $\mathrm{CO}$ pressure (shown most clearly for the data at $548 \mathrm{~K}$ ), in contrast with Equation R2, which says the order in CO should vary from +1 to -1 monotonically as $\mathrm{CO}$ pressure increases (and $\mathrm{CO}^{*}$ coverage increases from 0 to $1 \mathrm{ML}$ ). These deviations indicate that Equation R2, derived from Langmuir-Hinshelwood (L-H) assumptions, fails to correctly predict rates over wide ranges of pressure due to changes in rate and equilibrium 'constants' such as $\alpha$ and $K_{\mathrm{CO}}$, due to large co-adsorbate interactions between $\mathrm{CO}^{*}$ and CO-activation transition states (which affect $\alpha$ ) and other $\mathrm{CO}^{*}$ s (affecting KCO). These coadsorbate interactions cause deviations from the $\mathrm{L}-\mathrm{H}$ based equation only when $\mathrm{CO} *$ coverages are high, due to the crowding associated with such coverages. Furthermore, it suggests that CO* coverages rapidly exceed $0.5 \mathrm{ML}$ (CO begins to inhibit $\mathrm{CO}$ hydrogenation rates at less than 0.1 $\mathrm{kPa}$ for all three temperatures). Kinetic data thus indicates that $\mathrm{CO}^{*}$ coverages are $>0.5 \mathrm{ML}$ at all relevant conditions for FTS (which occur at much lower temperatures $(\sim 500 \mathrm{~K})$ and much higher pressures $(\sim 500 \mathrm{kPa} \mathrm{CO})$ than the point at which $\mathrm{CO}$ begins to inhibit methanation rates $(<0.1 \mathrm{kPa} \mathrm{CO})$. Further refinement of $\mathrm{CO}^{*}$ coverages is impossible to achieve from kinetic data alone due to the non-Langmuirian behavior that appears at high surface coverages of $\mathrm{CO}^{*}$. We then turn to in situ infrared spectroscopy as a method of measuring $\mathrm{CO}^{*}$ coverage explicitly. 


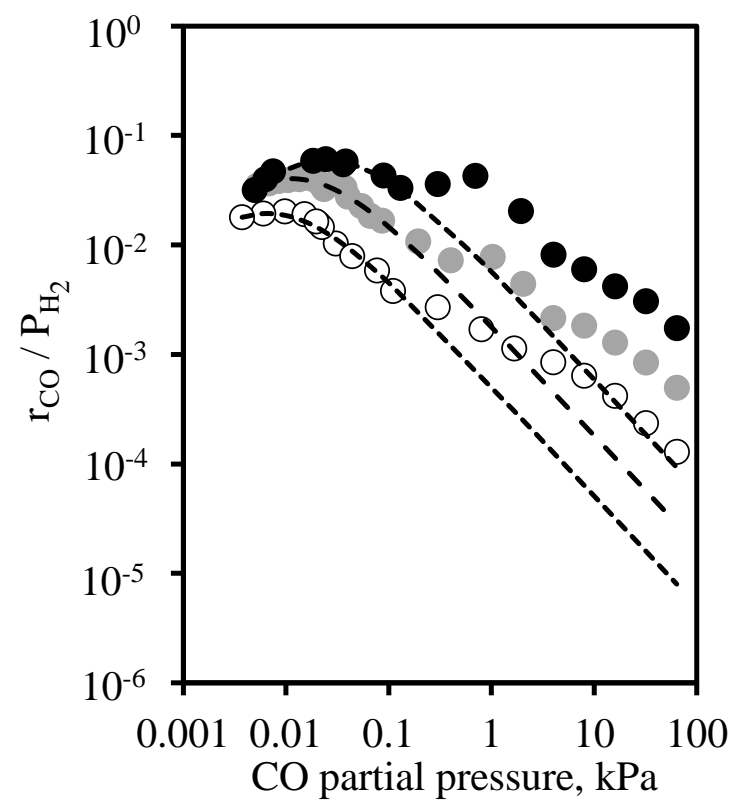

Figure $\mathrm{R} 2$. $\mathrm{CO}$ hydrogenation rate divided by $\mathrm{H}_{2}$ pressure as the function of $\mathrm{CO}$ partial pressures on $5 \%$ wt. $\mathrm{Ru} / \mathrm{SiO}_{2}(7.5 \mathrm{~nm}$ clusters) at different temperatures $(\bullet 598 \mathrm{~K}, \bullet 573 \mathrm{~K}$, ○ $548 \mathrm{~K}$, dash line is the trend line of predicted values using Langmuir-type rate equation 8)

Figure R3 shows CO adsorption isotherms, in which the $\mathrm{CO}$ intensity was computed by determining the area of the peak features associated with atop, bridge, and hollow-bound $\mathrm{CO}^{*}$ species on $\mathrm{Ru}$ surfaces. A Langmuir model accurately predicts the adsorption isotherm at low $\mathrm{CO}$ pressures ( $<0.5 \mathrm{kPa}$, Fig. R3a), and at higher $\mathrm{CO}$ pressures no further increase in adsorption intensity was observed, suggesting that $\mathrm{CO}^{*}$ coverages exceed $0.9 \mathrm{ML}$ at $\mathrm{CO}$ pressures $>0.5$ $\mathrm{kPa}$, the same critical CO pressure where the rate data began to deviate from the L-H model (Fig. R2). This in situ spectroscopy, along with the kinetic data presented above, indicate two things:

1) At the elevated temperatures ( 548 to $598 \mathrm{~K}$ ) associated with methanation, CO* coverages are in excess of $0.5 \mathrm{ML}$ at $\mathrm{CO}$ pressures less than $0.1 \mathrm{kPa}$ and approach $1 \mathrm{ML}$ at $\mathrm{CO}$ pressures $\sim 0.5$ $\mathrm{kPaCO}$.

2) From this, we can infer that at the conditions of FTS, with lower temperatures $(\sim 500 \mathrm{~K}, 50$ $100 \mathrm{~K}$ lower than those for methanation) and much higher pressures ( 500 $\mathrm{kPa} \mathrm{CO})$, the coverage of $\mathrm{CO}^{*}$ is expected to be near or even in excess of $1 \mathrm{ML}$. Supra-monolayer CO* species would likely form as di-CO* species on undercoordinated $\mathrm{Ru}$ atoms, and such species have been identified using infrared spectroscopy at higher CO pressures [Loveless, B; et al. J. Am. Chem. Soc. 2013, 135, 6107.]

3) Large co-adsorbate interactions caused by the crowded surfaces present during methanation (at $>1 \mathrm{kPa} \mathrm{CO}$ and 548-598 K) and FTS (at $\sim 500 \mathrm{kPa} \mathrm{CO}$ and $\sim 500 \mathrm{~K}$ ) prevent an accurate 
prediction of rate data from L-H style equations (Eq. R2) across very wide ranges of CO pressure.
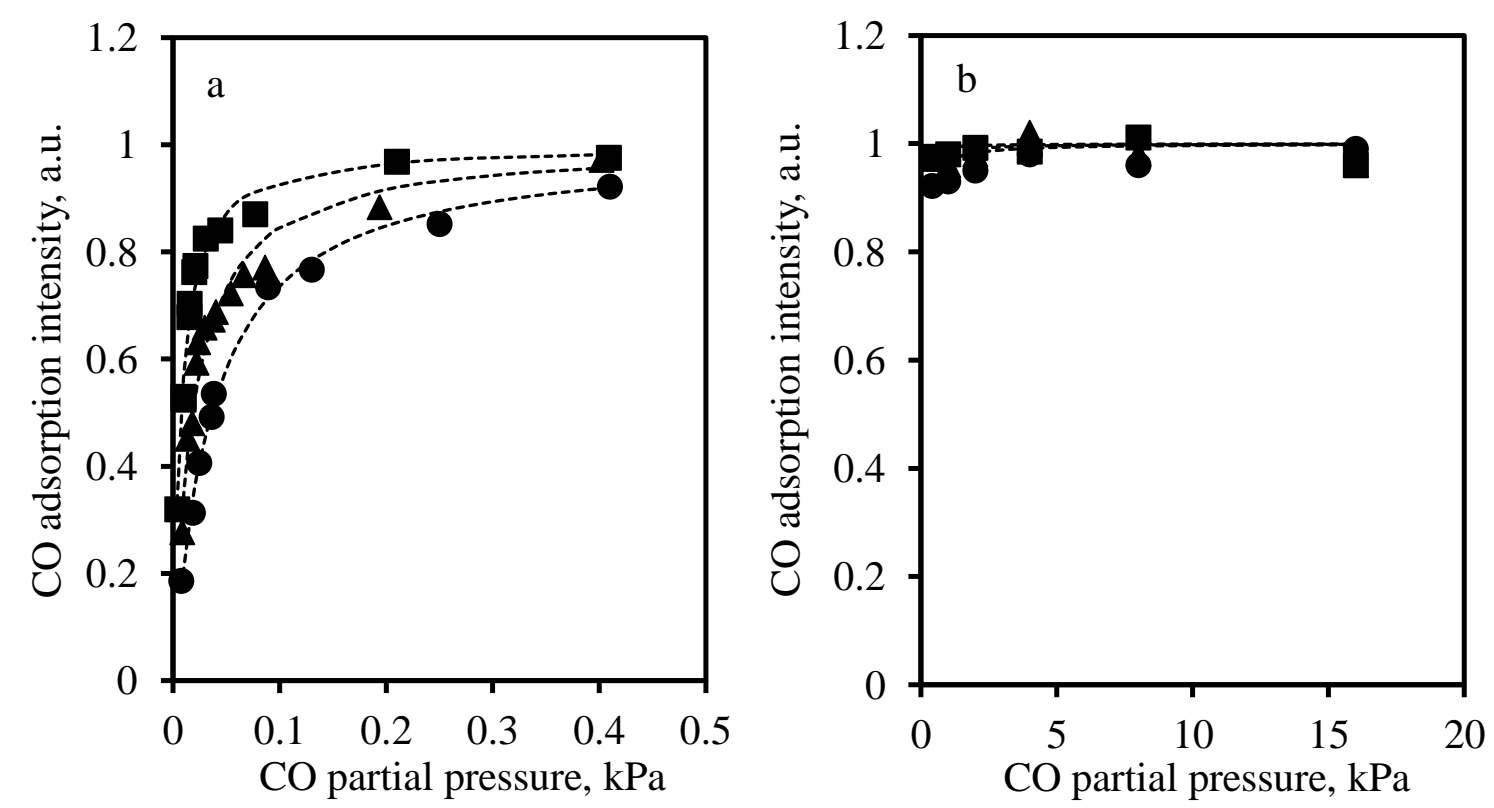

Figure R3. $\mathrm{CO}$ chemisorption isotherms during reaction on $5 \% \mathrm{wt}$. $\mathrm{Ru} / \mathrm{SiO}_{2}(7.5 \mathrm{~nm}$ clusters $)$ at different temperatures $\left(-548 \mathrm{~K}, \boldsymbol{\Delta} 573 \mathrm{~K}, \bullet 598 \mathrm{~K}\right.$; a, $0.01-0.4 \mathrm{kPa} \mathrm{CO}, 1-20 \mathrm{kPa} \mathrm{H}_{2}, 0.5-1.5$ $\mathrm{kPa} \mathrm{H}_{2} \mathrm{O}$; b, 0.4-16 kPa CO, 10-80 $\mathrm{kPa} \mathrm{H}_{2}, 1.5-16 \mathrm{kPa} \mathrm{H}_{2} \mathrm{O}$ ) 